\title{
Impact of North Atlantic Freshwater Forcing on the Pacific Meridional Overturning Circulation under Glacial and Interglacial Conditions
}

\author{
HYO-JEONG KIM AND SOON-IL AN \\ Department of Atmospheric Sciences/Irreversible Climate Change Research Center, Yonsei University, Seoul, South Korea
}

(Manuscript received 23 January 2019, in final form 29 April 2019)

\begin{abstract}
The Pacific meridional overturning circulation (PMOC) is not well known compared to the Atlantic meridional overturning circulation (AMOC), due to its absence today. However, considering PMOC development under different climate conditions shown by proxy and modeling studies, a better understanding of PMOC is appropriate to properly assess the past and future climate change associated with global ocean circulation. Here, the PMOC response to freshwater forcing in the North Atlantic (NA) is investigated using an Earth system model of intermediate complexity under glacial (i.e., Last Glacial Maximum) and interglacial [i.e., preindustrial with/without inflow through Bering Strait (BS)] conditions. The water hosing over NA led to the shutdown of the AMOC, which accompanied an active PMOC except for the preindustrial condition with the opening BS, indicating that the emergence of the PMOC is constrained by the freshwater inflow through the BS, which hinders its destabilization through enhancing ocean stratification. However, the closure of the BS itself could not explain how the sinking motion is maintained in the North Pacific. Here we found that various atmospheric and oceanic processes are involved to sustain the active PMOC. First, an atmospheric teleconnection associated with the collapsed AMOC encouraged the evaporation in the sinking region, causing buoyancy loss at the surface of the North Pacific. Second, the strengthened subpolar gyre transported saltier water northward, enhancing dense water formation. Finally, the vigorous upwelling in the Southern Ocean enabled a consistent mass supply to the sinking region, with the aid of enhanced westerlies.
\end{abstract}

\section{Introduction}

Density-driven ocean circulation, known as thermohaline circulation (THC), carries a large amount of energy across a hemisphere. Its main sinking branch at the present is located at the North Atlantic (NA) region. As the saltier ocean surface water from lower latitudes reaches the NA, it becomes denser by losing latent and sensible heat to the cold and dry air, and/or sometimes by brine rejection when sea ice is forming. This denser water permeates to the deep ocean to form North Atlantic Deep Water (NADW) and then comes back to the surface in the low latitudes and Southern Ocean by diapycnal mixing or wind-driven upwelling. This oceanic meridional circulation loop over Atlantic Ocean is often called the Atlantic meridional overturning circulation (AMOC). The AMOC is not solely driven by the density difference, but rather works in combination with wind forcing (Timmermann and Goosse 2004; Yang et al. 2016; Munk and Wunsch 1998; Wunsch 1998; Wunsch

Corresponding author: Soon-Il An, sian@yonsei.ac.kr and Ferrari 2004; Marshall and Speer 2012). Unlike in the Atlantic however, the current Pacific meridional overturning circulation (PMOC), as the AMOC counterpart, has no significant sinking motion over the North Pacific (Kawabe and Fujio 2010) and even shows upwelling, although it is very weak (Broecker 1997; Talley 2013). The absence of PMOC has been claimed to be due either to a well-developed halocline that prevented cold surface water from sinking, caused by relatively large net precipitation and weak salt advection (e.g., Warren 1983; Schmittner et al. 2011; Sinha et al. 2012; Emile-Geay et al. 2016), or to the relatively limited extension of the Pacific basin, compared with the poleward extension of Atlantic basin, leading to easy contact with colder polar air (von der Heydt and Dijkstra 2008).

Unlike the present climate, paleoclimatic records suggest that strong ventilation existed in the North Pacific region under different climate conditions (Okazaki et al. 2010; Knudson and Ravelo 2015; Burls et al. 2017). The existence of PMOC has also been supported by a number of modeling studies under a specific climate forcing (Saenko et al. 2004; Timmermann et al. 2005; 
Mikolajewicz et al. 2006; von der Heydt and Dijkstra 2006; Chikamoto et al. 2012; Hu et al. 2012a; Burls et al. 2017; Jackson et al. 2017). Note that PMOC resembles AMOC, except that PMOC is a source of an intermediate water rather than deep water. As PMOC either collapses or resumes, for example according to an external forcing, it could cause significant change in the climate of the surrounding area, as has happened when AMOC collapsed or suddenly recovered. For example, based on the model simulations, Liu and $\mathrm{Hu}$ (2015) showed that oceanic heat transport associated with a resumption of PMOC mitigated a southward shift of the intertropical convergence zone (ITCZ) in the Pacific, when AMOC shut down under the Heinrich Stadial 1 (HS1)-like forcing. Regional ITCZ displacement by PMOC reached up to $5^{\circ}$ in the Pacific, and thus the activation of PMOC modulated the Pacific climate. Furthermore, according to their study, the amount of northward oceanic heat transport by PMOC resumption corresponded to an offset by $0.5^{\circ}$ against a southward shift of the global ITCZ. While global ITCZ movement has often been linked to variations in AMOC strength, in a global energy constraint view (McGee et al. 2014; Schneider et al. 2014; Zhang and Delworth 2005; Frierson et al. 2013; Marshall et al. 2014), the work of Liu and $\mathrm{Hu}$ (2015) suggested that a deeper understanding of PMOC was necessary, in order to understand the relationship between the global ITCZ position and oceanic meridional overturning circulations.

A dynamic connection between AMOC and PMOC has been hypothesized in several studies (Chikamoto et al. 2012; Freeman et al. 2015; Mikolajewicz et al. 1997; Menviel et al. 2014). This connection implies that past or future changes of AMOC must, in turn, influence PMOC. On one hand, in a future climate, increased glacial meltwater discharge, especially from the Greenland ice sheet melting (Van As et al. 2014; Bakker et al. 2016; Böning et al. 2016), the reduction of sea ice formation (Park et al. 2015; Johannessen et al. 2004; Stroeve et al. 2012; Sévellec et al. 2017; Liu and Fedorov 2019; Liu et al. 2019), and the enhanced surface heat and freshwater flux in the subarctic Atlantic Ocean (Kim and An 2013; Boyer et al. 2007; Gregory et al. 2005) could lead to possible AMOC weakening, by reducing surface water density. Although reports have indicated there was a low chance of complete AMOC shutdown in the future (O. Hoegh-Guldberg et al. 2019), an AMOC slowdown, and its resultant cooling trend over the subarctic Atlantic Ocean (the "cold blob") were observed during the last century (Josey et al. 2018; Thornalley et al. 2018; Caesar et al. 2018). Moreover, Liu et al. (2017) have argued that, as modeling bias has commonly favored a stable AMOC, the possibility of a collapsed
AMOC in a warming climate has been overlooked. A collapsed AMOC under higher warming climate conditions also appeared in simulations in some Earth system models of intermediate complexity, and in some flux-adjusted, full atmosphere-ocean coupled general circulation models (GCMs) (Meehl et al. 2007). Therefore, the possibility of an AMOC shutdown under a future warmer climate cannot be simply ignored.

On the other hand, near complete AMOC shutdowns very likely occurred during the Younger Dryas (YD) and Heinrich events (Flower et al. 2013; Aharon 2003; Böhm et al. 2015), and sometimes PMOC resumption occurred at the same time (Max et al. 2014; Chikamoto et al. 2012; Freeman et al. 2015; Menviel et al. 2014). Modeling studies have proposed mechanisms for this seesaw behavior, involving atmospheric transmission (Mikolajewicz et al. 1997; Okazaki et al. 2010) or oceanic teleconnection (Jackson et al. 2017; Saenko et al. 2004; Cessi et al. 2004; Timmermann et al. 2005), or a combination of the two (Mikolajewicz et al. 1997; Timmermann et al. 2005).

There has also been conflicting evidence from radiocarbon (Sarnthein et al. 2013) and planktonic foraminifera- and alkenone-based temperature reconstructions (Praetorius and Mix 2014; Max et al. 2012), however, which implies an in-phase relationship between the Atlantic and the Pacific. Therefore, we considered that it was necessary to improve understanding of the PMOC generation mechanism, and of any linkage between PMOC and AMOC, by using climate model simulations, and applying a sensitivity experiment-a so-called water hosing experiment-in particular under the various boundary conditions.

The remainder of this paper has been organized as follows: In section 2, we have introduced the model and the experimental settings. In section 3 , the unperturbed states under different boundary conditions have been analyzed. Then, the conditions under which PMOC developed and the physical processes to maintain it have been discussed. Further discussions and a summary are presented in section 4 and section 5, respectively.

\section{Experiments}

In this study, version 1.3 of the LOch-Vecode-EcbiltCLio-agIsm model [LOVECLIM; please see Goosse et al. (2010) for more information about the model and its constituent parts] was used. This intermediate complexity Earth system model originally consisted of five components. However, for our purposes, the atmosphere, ocean with sea ice, and terrestrial vegetation models were used, and the ice sheet and the carbon cycle models were deactivated. 
TABLE 1. A summary of experimental settings.

\begin{tabular}{llcl}
\hline \hline Experiment & \multicolumn{1}{c}{ I. Other than II } & II. Bering Strait & \multicolumn{1}{c}{ III. Forcing } \\
\hline PI CTL & Preindustrial & Open & None \\
PI FWF & Preindustrial & Open & Freshwater release in the NA \\
LGM CTL & The Last Glacial Maximum & Closed & None \\
LGM FWF & The Last Glacial Maximum & Closed & Freshwater release in the NA \\
PI_BC CTL & Preindustrial & Closed & None \\
PI_BC FWF & Preindustrial & Closed & Freshwater release in the NA \\
\hline
\end{tabular}

The atmospheric part of LOVECLIM (ECBilt; Opsteegh et al. 1998) solves the quasigeostrophic potential vorticity equation, using a spectral method. Its horizontal grid system follows T21 truncation, equivalent to $5.6^{\circ}$ resolution, while the vertical grid has three levels, at 800,500 , and $200 \mathrm{hPa}$. The model uses flux corrections for surface freshwater flux to remove excessive precipitation in the Atlantic and to supplement deficiency in the Pacific. The ocean model, CLIO (Goosse and Fichefet 1999), is an ocean GCM composed of primitive equations. The model uses a B-grid with a horizontal resolution of $3^{\circ}$ and has 20 levels, unevenly stratified over a depth of $5500 \mathrm{~m}$. Because of a singularity problem at the North Pole, the NA and the Arctic Oceans consist of a rotated subgrid, which precludes direct water exchange between the Pacific and the Arctic through the Bering Strait (BS) - and so the throughflow is parameterized, based on a predefined coefficient. For a given freshwater flux (FWF), the model responds by changing the vertical velocity in the ocean $(W=$ evaporation - precipitation - runoff $)$, as it has a free surface.

The terrestrial vegetation model (VECODE; Brovkin et al. 1997) was also switched on. VECODE has the same resolution of ECBilt, in which the plant functional type (PFT) classification was utilized with just two types: trees and grasses.

To compare climate responses under different boundary conditions, control (CTL) simulations were first performed under the preindustrial and Last Glacial Maximum (LGM) conditions (Table 1). Starting from the preindustrial initial state, the preindustrial (PI) CTL run was continued for 2000 years, while the LGM CTL was run for 4000 years (as it needed more time to adjust to its boundary conditions and to reach equilibrium). For the LGM simulation, we adopted the Paleoclimate Modeling Intercomparison Project 2 (PMIP2; Braconnot et al. 2007) protocol. Changes to boundary conditions for the LGM simulations were as follows: lower greenhouse gas (GHG; $\mathrm{CO}_{2}, \mathrm{CH}_{4}$, and $\mathrm{N}_{2} \mathrm{O}$ ) concentrations, adjustment of orbital parameters (smaller obliquity, and larger eccentricity and precession index), ice sheet distribution in accordance with the ICE-5G dataset (Peltier 2004), and changes in oceanic bathymetry and coastal lines. The major coastal lines difference between the LGM and PI runs was the opening or closing of the BS. As a part of the sensitivity test, we also conducted an experiment with preindustrial boundary conditions, but with the BS closed (the BS is a channel for mass exchange between the Pacific and the Arctic sea), called PI_BC. The PI_BC control simulation was run for 2000 years, starting from the preindustrial initial condition.

In a simulation forcing, a "water hosing experiment," using spatially and temporally identical freshwater forcing, was imposed onto the last time step of each CTL experiment. Thus, we perform six experiments, two for each boundary condition, and the experimental suite has been summarized in Table 1. For the forced simulations (FWF in Table 1), the freshwater flux was evenly distributed in the NA, between $50^{\circ}$ and $70^{\circ} \mathrm{N}$. Its magnitude linearly increased from 0 to $1 \mathrm{~Sv}\left(1 \mathrm{~Sv} \equiv 10^{6} \mathrm{~m}^{3} \mathrm{~s}^{-1}\right)$ for the first 2000 years, and then started to decrease at the same rate, down to $-0.4 \mathrm{~Sv}$ for the next 2800 years (Hawkins et al. 2011). The amount of total freshwater flux used in this study is relatively large compared to those implied by paleo-records (Marson et al. 2014; Fairbanks 1989; Deschamps et al. 2012), but the amount was chosen based on the model's sensitivity to the freshwater forcing (Kienast et al. 2013; Kageyama et al. 2013) since our goal is to explore physical processes in climate response to the forcing. Under such forcing, the AMOC collapsed under all three conditions (PI, LGM, and PI_BC) within 1000 years (Fig. 1, navy blue lines) and entered a stable state. For the analysis, the periods between the model years 2000 and 2200 (the shaded intervals in Fig. 1), which belonged to the inactive AMOC state, have been used and compared with the CTL runs. We noted that the results were not sensitive to the choice of window.

The experimental suite in Table 1 allowed systematic comparison between different boundary conditions. The differences between the forced PI and LGM experiments suggested that climate response significantly depended on the equilibrium state under a given boundary condition, even though the forcing was the same. Then, 
(a) $\mathrm{PI}$

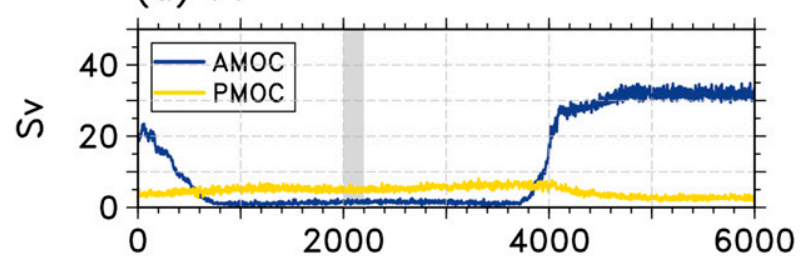

(b) LGM

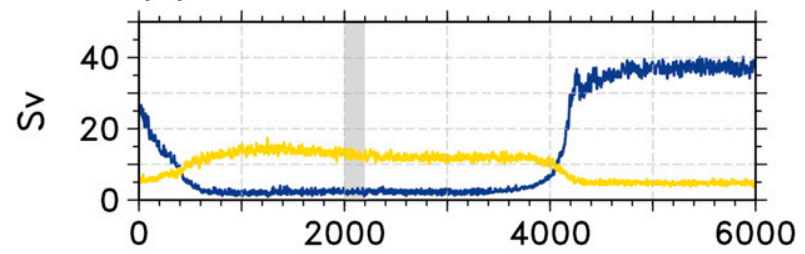

(c) PI_BC

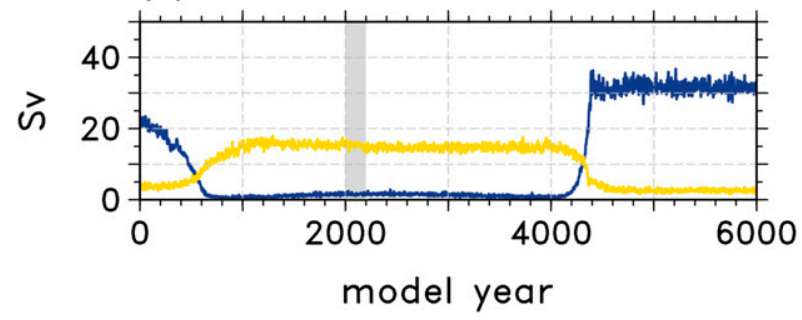

FIG. 1. Time series of the maximum meridional streamfunction (Sv; Sv indicates a volume transport unit of $10^{6} \mathrm{~m}^{3} \mathrm{~s}^{-1}$ ) in the Atlantic (navy blue) and in the Pacific (yellow) oceans obtained from the (a) PI, (b) LGM, and (c) PI_BC experiments. Utilized period is indicated by shading.

by comparing the PI and PI_BC cases, we could isolate the effect of BS among the various boundary condition components. The similarity in the LGM and PI_BC runs also helped assess the robustness of the BS effect. Although we did not perform a sensitivity test for every boundary condition component, the results in section 3 have shown that the BS played a crucial role in determining PMOC behavior when the freshwater flux was applied to the NA.

\section{Results}

\section{a. Control simulations}

Prior to discussing the forced simulations, we compare results from the unforced experiments (CTL in Table 1). Figure 2 shows the mean surface temperatures obtained from each experiment for 200 years. Basically, the surface temperature for the LGM control run showed much colder environment, especially in the higher latitudes, than those for PI and PI_BC. The lower temperature may have been due to the low GHG concentration (95 ppmv, 410 ppbv, and 70 ppbv lower $\mathrm{CO}_{2}, \mathrm{CH}_{4}$, and $\mathrm{NO}_{2}$ than PI, respectively). The widely distributed

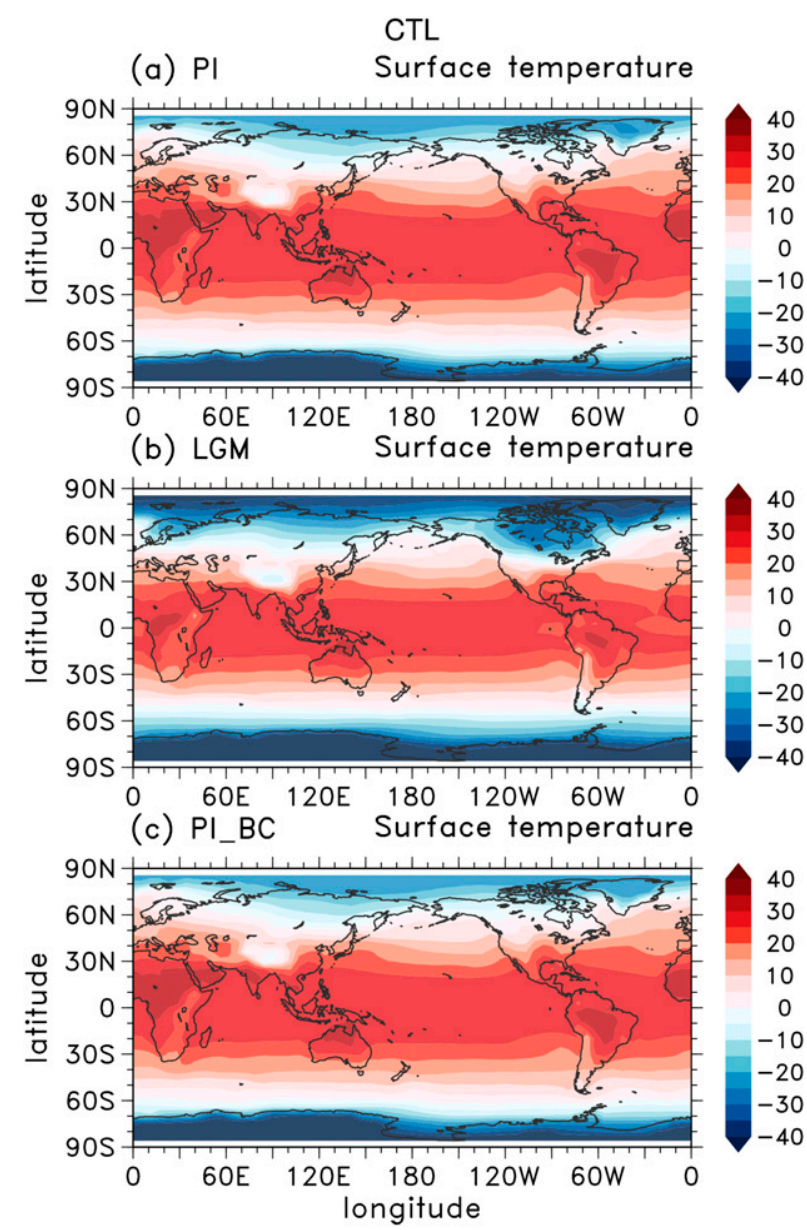

FIG. 2. Mean surface temperature distribution (color bar; ${ }^{\circ} \mathrm{C}$ ) averaged over 200 years obtained from the (a) PI, (b) LGM, and (c) PI_BC control experiments. The selected 200 -yr periods are marked in Fig. 1 as gray color shading.

continental ice sheets and sea ice aggravated cooling of the high-latitude surfaces, through ice-albedo feedback. The closure of the BS in PI_BC did not result in a noticeable change, compared to that of PI, showing a slight warming over the Arctic region (Figs. 2a,c).

Similar to the surface temperature, AMOC did not seem much affected by the BS closure either (Fig. 3). The core location and strength of the overturning cells in Figs. $3 \mathrm{a}$ and $3 \mathrm{c}$ are highly analogous to each other. For the LGM case, the meridional extent of the AMOC retreated slightly to the south, possibly due to the sea ice extent. The mean intensity of AMOC, defined as the maximum annual mean streamfunction, north of $20^{\circ} \mathrm{N}$, was stronger in the LGM simulation by $\sim 4 \mathrm{~Sv}$. The more vigorous AMOC during the Last Glacial Maximum was consistent with the results from the eight models of phase 3 of the Paleoclimate Model Intercomparison Project (PMIP3; Braconnot et al. 2012; Marzocchi and 

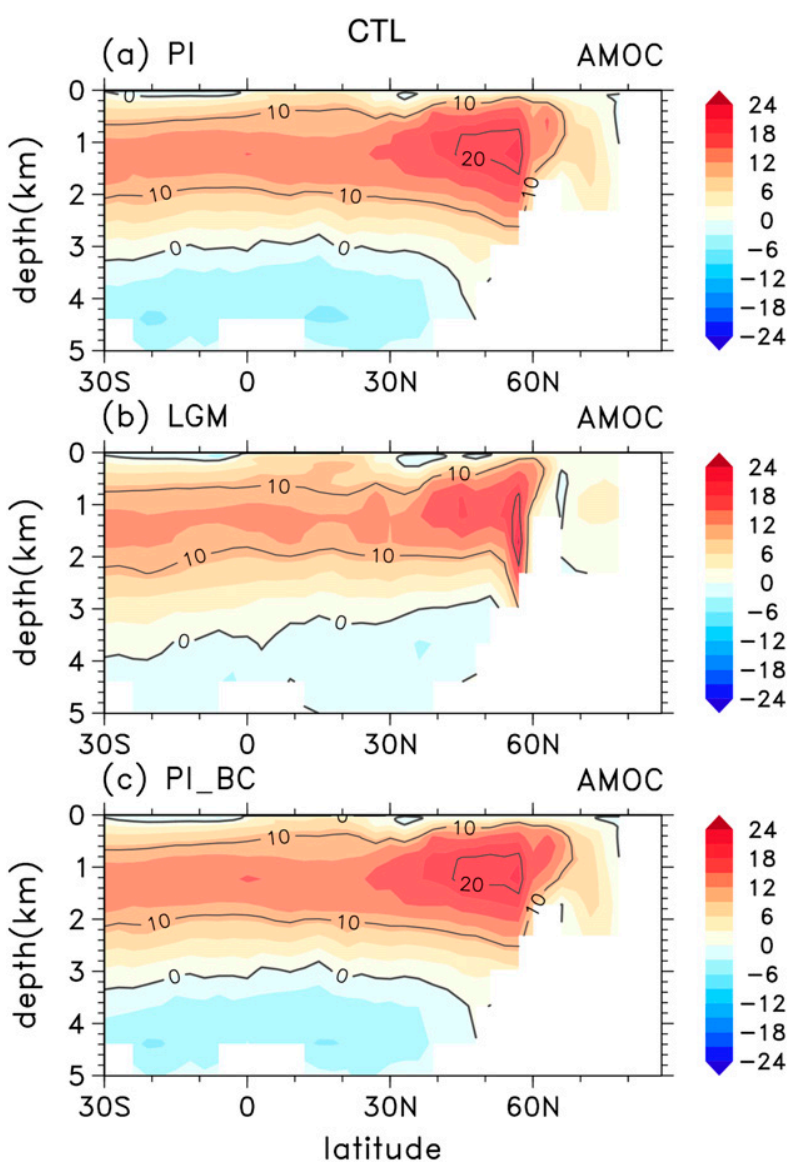

FIG. 3. Zonally integrated mean meridional streamfunction (color bar; Sv) for the Atlantic basin obtained from the (a) PI, (b) LGM, and (c) PI_BC control experiments. Positive values denote clockwise circulation.

Jansen 2017; Muglia and Schmittner 2015). On the other hand, the intrusion of Antarctic Bottom Water (AABW) was weaker in the LGM simulation, by $\sim 5 \mathrm{~Sv}$, compared to the other two cases. The weaker AABW in LGM CTL, compared with PI CTL, was consistent in five out of the eight PMIP3 models (Muglia and Schmittner 2015).

In Fig. 4c, the unforced simulation PMOC structures are shown as the meridional streamfunction, zonally averaged over the Pacific basin. Under the preindustrial condition, a weak counterclockwise circulation existed in the deep ocean of the Pacific, regardless of BS opening or closing. Shallow, symmetrical overturning cells were also found centered on the equator across the tropics. In LGM CTL, a clockwise circulation was observed in the deep ocean, in contrast with the PI and PI_BC results. However, an active sinking motion at the surface, as seen in the Atlantic Ocean (Fig. 3), did not feature, indicating that a well-organized PMOC was not identified in all control experiments. Therefore, we concluded that PMOC was missing in all the CTL experiments.

\section{b. Forced simulations}

Figure 1 (yellow lines) depicts temporal evolutions of PMOC in the forced simulations as the maximum meridional streamfunction in the Pacific north of $20^{\circ} \mathrm{N}$, below 500-m depth. In LGM FWF and PI_BC FWF, an active PMOC with an intensity of more than $10 \mathrm{~Sv}$ was observed during the period of analysis (the shaded intervals in Fig. 1), showing an antiphase relationship with AMOC. On the other hand, PMOC in the PI FWF experiment remained inactive for the entire period of that the forcing was applied.

Mean PMOCs obtained from the forced simulations are displayed in Figs. 4d-f. In PI FWF, there was no systematic PMOC circulation structure, whereas in the LGM FWF and PI_BC FWF experiments a clockwise circulation cell, with a sinking branch at the North Pacific, was found within the upper $2 \mathrm{~km}$. The downward branches kept flowing to the south, and reached the Southern Hemisphere ( $\mathrm{SH})$. On their way back at the surface, it partially merged with another clockwise circulation associated with the equatorial upwelling, that is, a subtropical shallow meridional overturning cell (STC), and thus it had two cores, one in the Northern Hemisphere $(\mathrm{NH})$ subtropics and the other at $40^{\circ}-50^{\circ} \mathrm{N}$. However, the differences between the CTLs and the forced simulations (FWFs) (Figs. 4h,i) show development of a circulation where the water descended in the North Pacific, flowed across the equator at intermediate depths, upwelled in the $\mathrm{SH}$, and flowed back to the north slightly below the surface. On the other hand, the PI response (Fig. 4g) did not show such structure. Although the anomalous positive streamfunctions were dominant in the PI FWF simulation, it was mainly confined to the bottom layer, representing a collapse of the pre-existing circulation (the counterclockwise flow in Fig. 4a). The forced PI_BC response (Fig. 4i) resembled a linear combination of the forced PI (Fig. 4g) and the forced LGM responses (Fig. 4h).

To understand the mechanism of the PMOC emergence due to freshwater forcing over the North Atlantic Ocean, we analyzed surface freshwater flux (precipitation minus evaporation $P-E$ ). Positive values in Fig. 5 (blue shading) indicate the increase of surface freshwater flux, and vice versa. As shown in Fig. 5, the northern North Pacific, between $40^{\circ}$ and $60^{\circ} \mathrm{N}$, became drier in the forced LGM and PI_BC simulations, compared to the unforced simulations. The change in surface freshwater flux reached $\sim 0.5 \mathrm{~mm} \mathrm{day}^{-1}$ for both simulations in this region, which was substantial considering that the unperturbed mean states showed an order of 

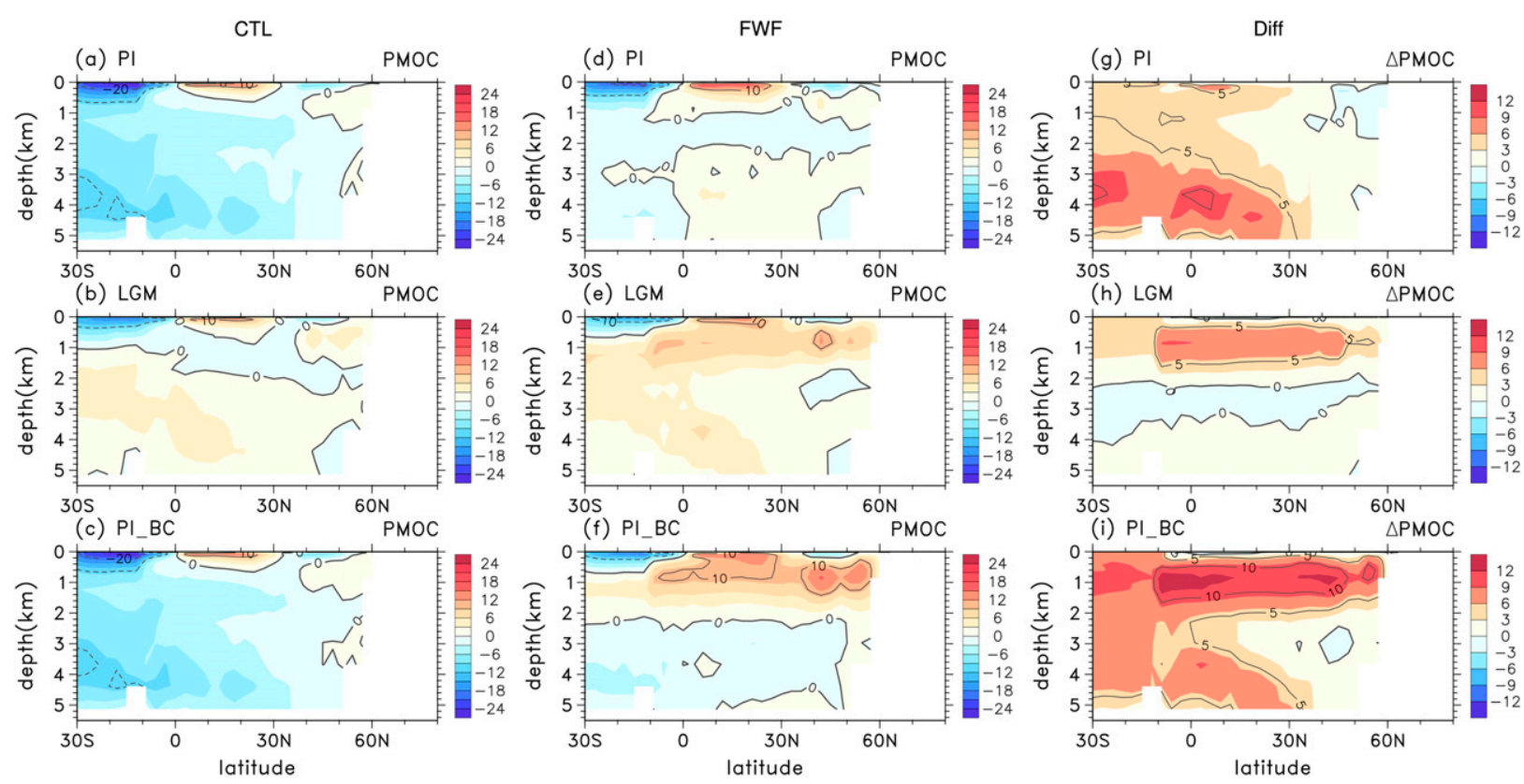

FIG. 4. Zonally integrated mean meridional streamfunction (color bar; Sv) in the Pacific basin (a)-(c) for the control experiments and (d)-(f) for the forced experiments. (g)-(i) The differences (forced minus control) for each boundary condition. Positive values denote clockwise circulation. Contour intervals are $10 \mathrm{~Sv}$ for (a)-(f) and $5 \mathrm{~Sv}$ for (g)-(i).

$1 \mathrm{~mm}$ day $^{-1}$; we also saw that the change in $P-E$ in the PI_BC experiment was greater than that in the LGM case. The forced PI (Fig. 5a) simulation also showed some drier conditions, but its magnitude was comparatively small.

The reduced surface freshwater flux in the northern North Pacific, in both forced LGM and PI_BC simulations, partly came from decrease in precipitation. In these two simulations, anomalous high pressure at the surface expanded from the Eurasian continent toward the northwestern Pacific, while anomalous low pressure developed over the northeastern Pacific, after freshwater flux was injection to the Atlantic (Figs. 6b,c). The eastward zonal pressure gradient anomaly induced northerly winds, which led to intrusion of a cold, dry Arctic air mass into the North Pacific.

Reduction in the baroclinicity was another element that contributed to the dryness. The sea surface temperature (SST) over the west of the date line increased between $50^{\circ}$ and $60^{\circ} \mathrm{N}$, while it decreased in the midlatitudes (Figs. 7b,c). It weakened the climatological SST contrast, which was organized by cold temperature along the southeast coast of eastern Siberia, and relatively warm temperature to the east of Japan. The Eady growth rate, a measurement of baroclinic instability (Eady 1949; Lindzen and Farrell 1980; Simmonds and Lim 2009), showed that the reduced SST gradient between $40^{\circ}$ and $50^{\circ} \mathrm{N}$ in the North Pacific resulted in the (a) PI

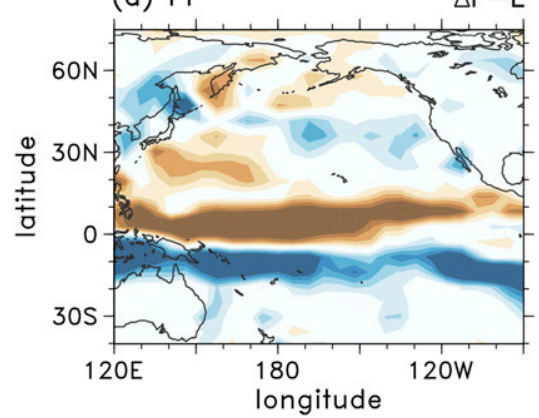

(b) LGM

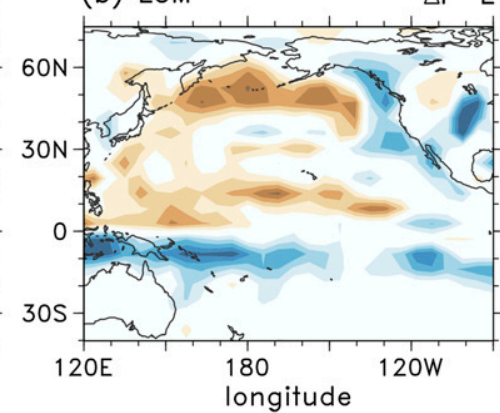

(c) PI_BC

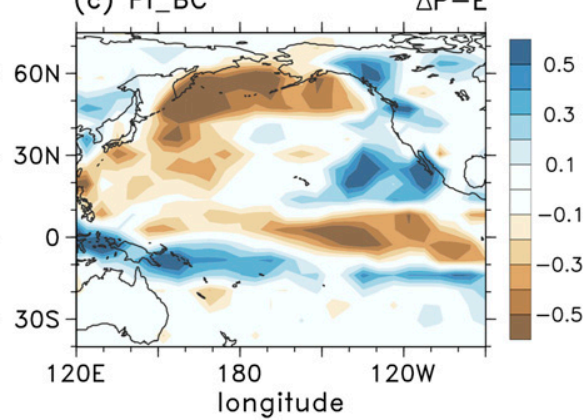

FIG. 5. Changes in mean surface freshwater flux (precipitation minus evaporation; $\mathrm{mm} \mathrm{day}^{-1}$ ) over the Pacific after the freshwater forcing in (a) PI, (b) LGM, and (c) PI_BC. 
(a) PI

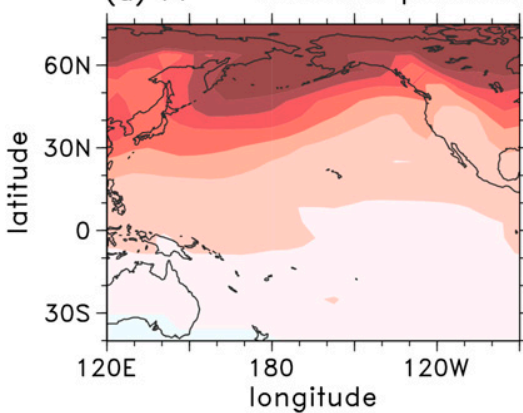

(b) LGM $\triangle$ Surface pressure

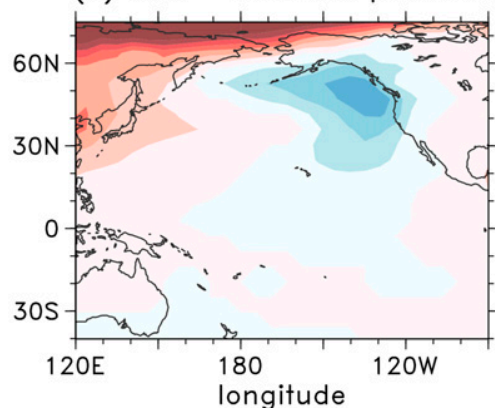

(c) PI_BC $\triangle$ Surface pressure

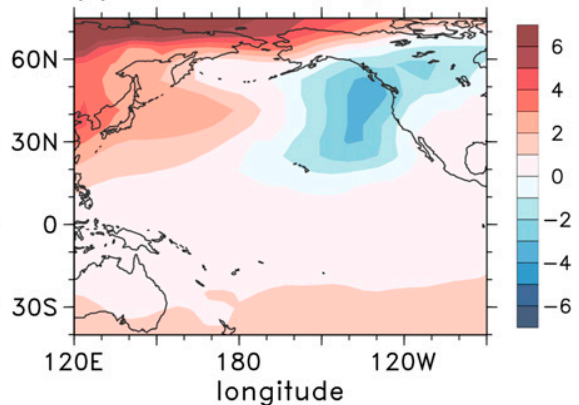

FIG. 6. As in Fig. 5, but for the surface pressure (hPa).

decrease of baroclinicity in that region (Figs. 8b,c). With the decreased baroclinicity, eddy growth and storm track activity were also weakened (Sung et al. 2014; Sampe et al. 2010; Timmermann et al. 2014), thus reducing precipitation.

Aside from decreased precipitation $P$, increased evaporation $E$ also contributed to the reduction of surface freshwater flux $P-E$, in the northern North Pacific, in the LGM and PI_BC simulations. The anomalous evaporation pattern in the midlatitudes (not shown) coincided with the anomalous SST pattern, which resembled the positive phase of the Pacific decadal oscillation (PDO) (Mantua et al. 1997; Deser et al. 2010; Newman et al. 2016). This implied that evaporation in this area might have been primarily related to the local SST. To the west of the date line, the area of increased evaporation overlapped the area of decreased precipitation, leading to a synergy to intensify the surface freshwater flux reduction. On the other hand, to the east of the date line, precipitation increased along the west coast of America, but evaporation overcompensated for the increased precipitation, so the surface freshwater flux was negative.

The PI run also depicted a large expansion of high pressure in the overall middle to high latitudes (Fig. 6a). Accordingly, a reduction in precipitation also manifested. However, the decreased evaporation caused by the prevailing cooling in the North Pacific (Fig. 7a) rather cancelled this out, and thus only minor changes in surface freshwater flux appeared in the PI case (Fig. 5a).

To investigate the buoyancy-forcing change due to the evaporation, vertical density and salinity distributions averaged between $50^{\circ}$ and $60^{\circ} \mathrm{N}$ are shown in Fig. 9, where, for the sake of simplicity, deviations from a reference value of $1-\mathrm{km}$ depth are represented. The vertical density gradients in the active PMOC cases of the LGM FWF and PI_BC FWF simulations (red lines in Figs. 9c,e) were mitigated, compared to those in the CTL runs (black lines in Figs. 9c,e), in accordance with the reduced surface freshwater flux. The well-mixed feature is also visible in the salinity profiles. Figures $9 \mathrm{~d}$ and $9 \mathrm{f}$ show that the haloclines diminished after the freshwater forcing was engaged. Taken together, the enhanced moisture transfers from ocean to air made the surface

(a) PI $\triangle \mathrm{SST}$

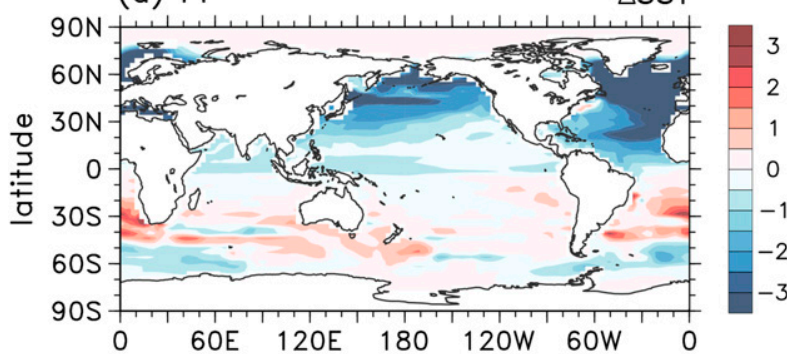

(b) LGM $\triangle \mathrm{SST}$

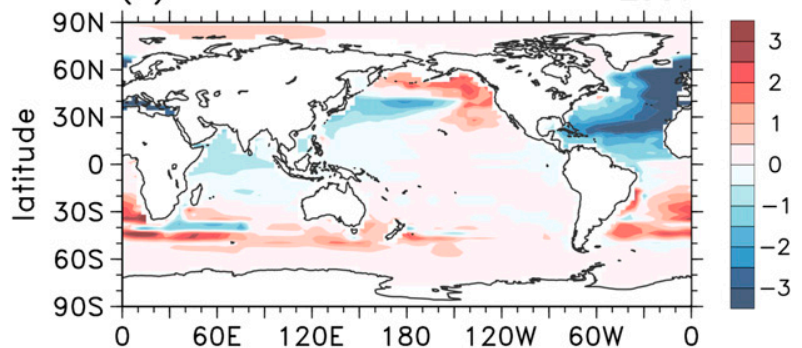

(c) PI_BC $\triangle \mathrm{SST}$

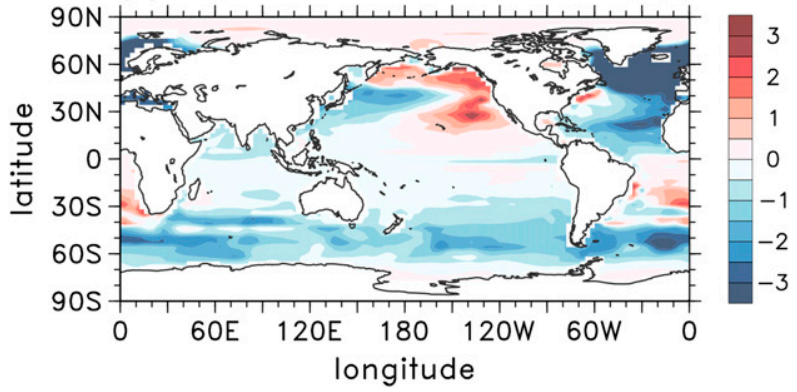

FIG. 7. Changes in mean SST (color bar; ${ }^{\circ} \mathrm{C}$ ) after the freshwater forcing for (a) PI, (b) LGM, and (c) PI_BC. 
(a) PI

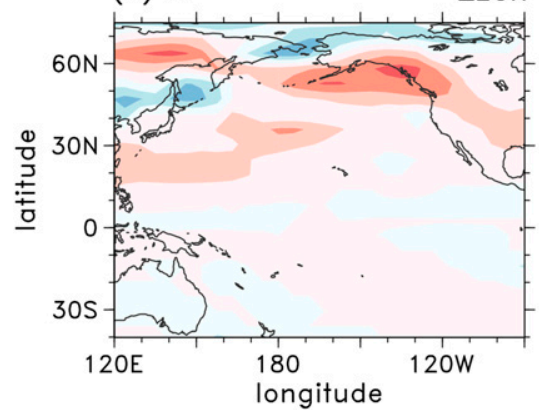

(b) LGM

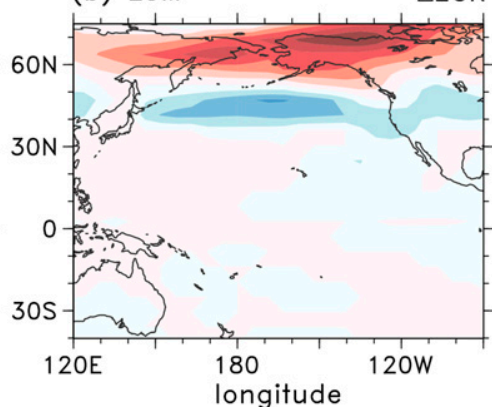

(c) PI_BC

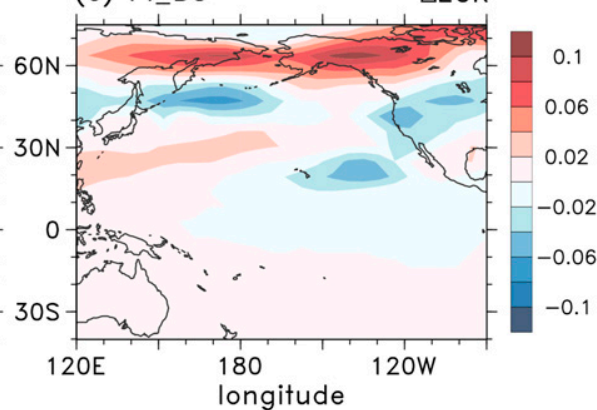

FIG. 8. As in Fig. 5, but for the baroclinic instability measured using the Eady growth rate $\left(\right.$ day $\left.^{-1}\right)$.

water lose buoyancy. Subsequently, the sinking motion of PMOC was encouraged, and as the sinking stimulated exchange between the upper and lower waters, it lessened the density gradient in the interior, diminished the halocline slope, and deepened the mixed layer depth (MLD; Fig. 10).

This series of processes could be self-sustained under constant surface buoyancy forcing. If the surface (a) $\mathrm{PI}$

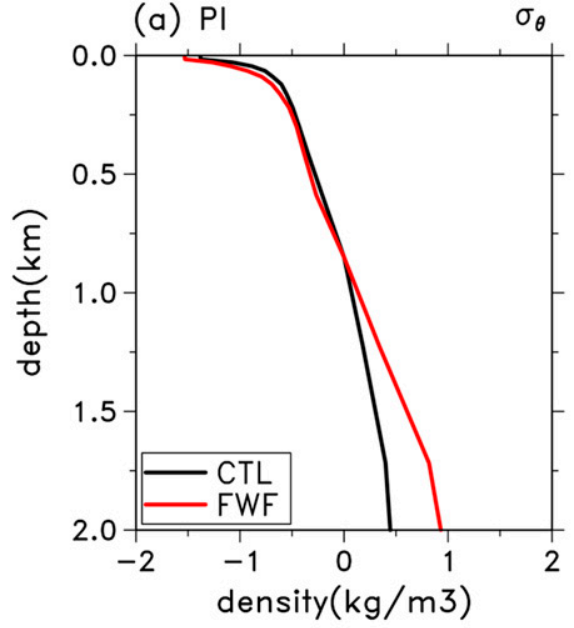

(b) $\mathrm{PI}$

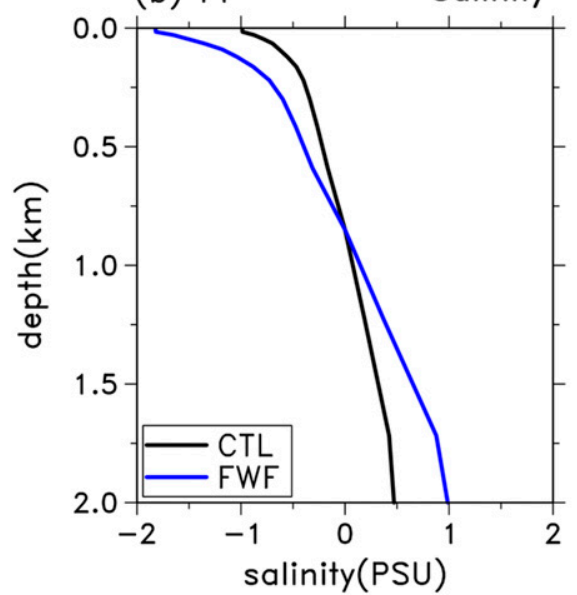

(c) LGM

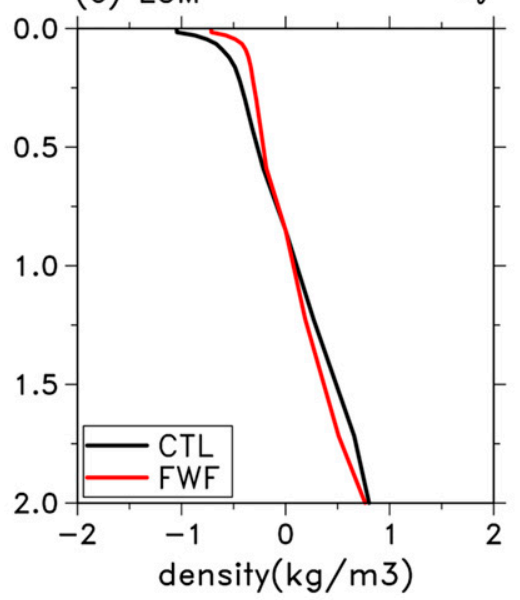

(d) LGM

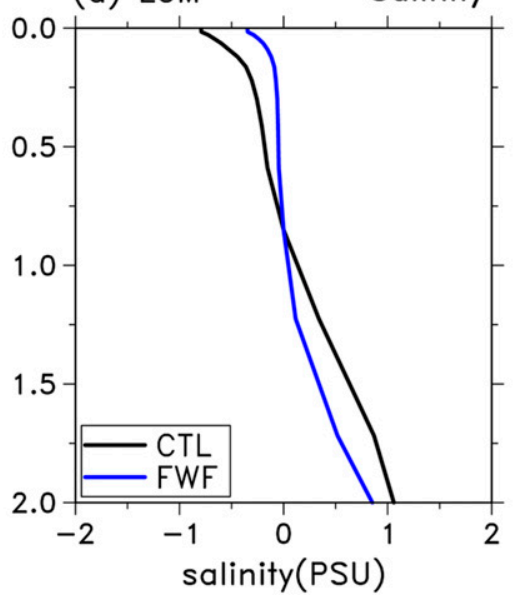

(e) PI_BC

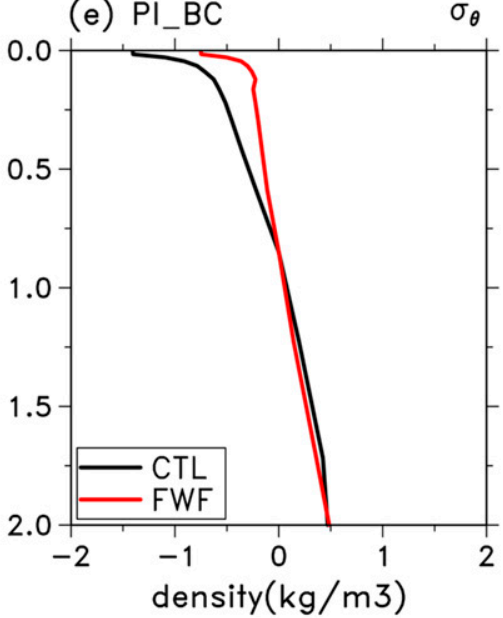

(f) PI_BC

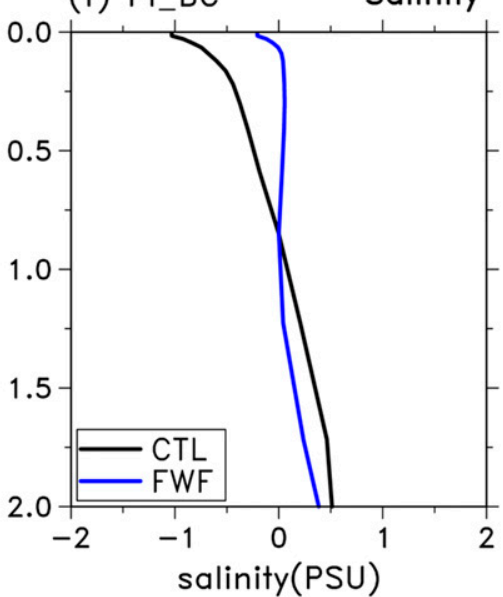

FIG. 9. (a) Mean vertical profile of potential density of seawater $\left(\mathrm{kg} \mathrm{m}^{-3}\right)$ in the Pacific between $50^{\circ}$ and $60^{\circ} \mathrm{N}$, shown as deviations from the reference value at 1000-m depth of the PI simulations. Black and red lines represent CTL and FWF, respectively. (b) As in (a) but for salinity [practical salinity units (psu)], with blue representing FWF. (c),(d) As in (a) and (b), but for LGM. (e),(f) As in (a) and (b), but for PI_BC. 
(a) PI

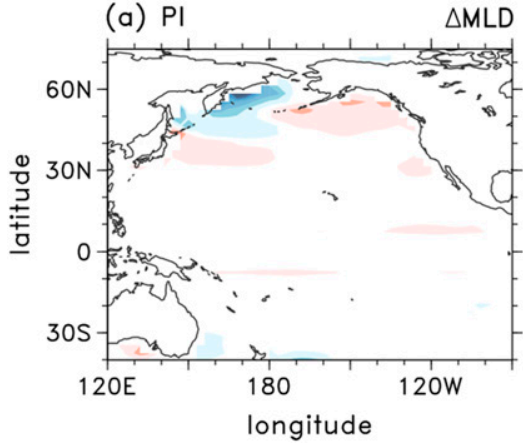

(b) LGM

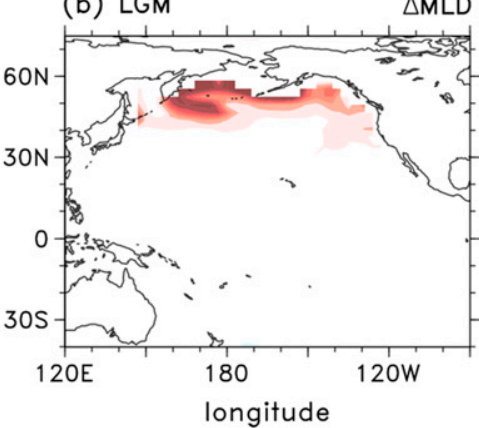

(c) PI_BC

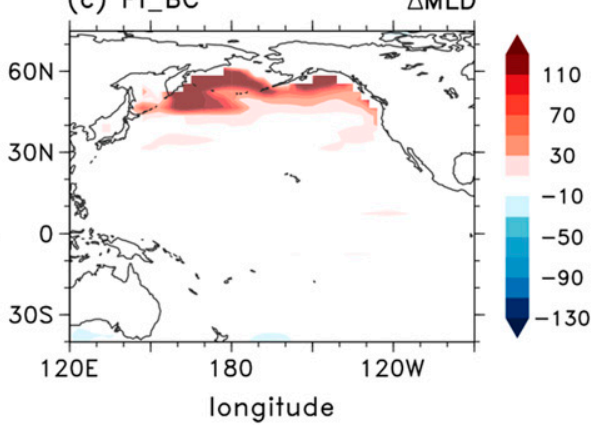

FIG. 10. As in Fig. 5, but for the MLD (m). MLD is defined as the depth at which the potential density of the ocean exceeds that of the sea surface by $0.02 \mathrm{~kg} \mathrm{~m}^{-3}$.

buoyancy forcing is fixed as in Figs. $5 b$ and $5 c$, the sinking motion can further be stimulated when the oceanic stratification is weaker. Therefore, as the ocean stratification is mitigated as in Figs. 9c and 9e, the surface buoyancy loss shown in Figs. $5 \mathrm{~b}$ and $5 \mathrm{c}$ can more effectively induce a vertical motion.

On the contrary, stratification was strengthened in the PI case of inactive PMOC (Figs. 9a,b). Even though the surface buoyancy forcing slightly increased between $50^{\circ}$ and $60^{\circ} \mathrm{N}$ of the North Pacific (Fig. 5a), the freshwater inflow to the Pacific through the open BS reduced surface water density (shown later in this section). It intensified the vertical density gradient and the surface buoyancy loss was not enough to overcome it, such that the PMOC sinking motion did not develop.

Before introducing another process on PMOC formation, it may be useful to discuss the roles of AMOC and PMOC with regard to global energy transport and the ITCZ. As seen in Fig. 5, by adding freshwater flux in the NA, net precipitation decreased in the northern tropics and increased in the southern tropics, around the equator. This hemispheric contrast was related to the southward shift of the ITCZ, as the northward heat transport by AMOC also ceased associated with shutdown of AMOC. Provided that the top of atmosphere (TOA) radiation does not perfectly compensate the hemispheric asymmetry in the energy budget (e.g., through albedo change, etc.), the atmosphere must additionally convey heat to the north (Schneider et al. 2014; McGee et al. 2014). Therefore, it resulted in a southward migration of the ITCZ (Held 2001; Donohoe et al. 2013) not only in the Atlantic, but also in the Pacific. If PMOC were activated at this point, it could mitigate the southward ITCZ shift in the Pacific, as Liu and $\mathrm{Hu}$ (2015) suggested, because the northward oceanic heat transport by PMOC could partially compensate the energy loss by the weakened AMOC. Indeed, the ITCZ movement was most prominent in the PI FWF (Fig. 5a) where PMOC was not activated.
Another process supporting PMOC development was salinity influx into the sinking region through the gyre circulation in the ocean, associated with so-called salt advection feedback (Stommel 1961). Meridional freshwater transport by the gyre circulation $W_{\text {gyre }}$ can be expressed by

$$
W_{\mathrm{gyre}}=-\frac{1}{S_{0}} \int\left\langle v^{\prime} S^{\prime}\right\rangle d z
$$

where $S$ and $v$ represent salinity and meridional current, respectively; $S_{0}$ is a reference salinity; the prime and angle bracket denote a deviation from the zonal mean and a zonal integration, respectively. (Rahmstorf 1996; de Vries and Weber 2005; Bitz et al. 2007; Liu and Liu 2013). Positive $W_{\text {gyre }}$ at the southern boundary represents freshwater import into the basin, and vice versa. The calculated values of $W_{\text {gyre }}$ at $46.5^{\circ} \mathrm{N}$ in the Pacific are shown in Fig. 11. The latitude of $46.5^{\circ} \mathrm{N}$ was chosen because the transport across this latitude is thought to be directly related to the freshwater budget in

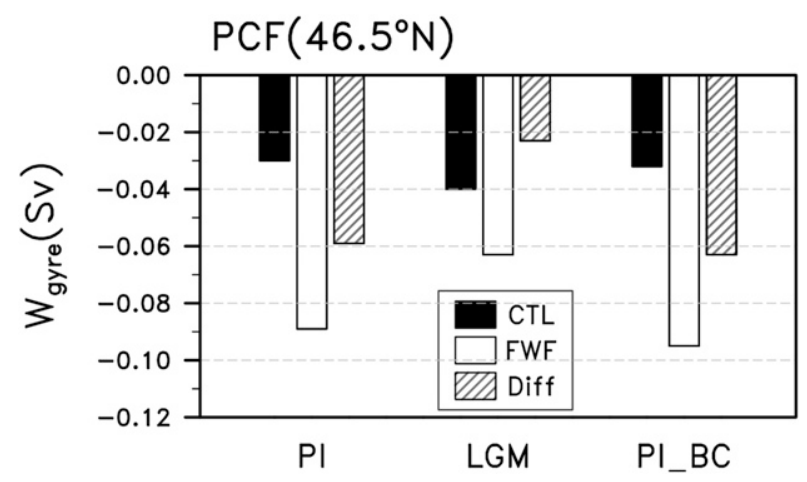

FIG. 11. Freshwater transport by the gyre circulation across $46.5^{\circ} \mathrm{N}$ in the Pacific (Sv). Black and white bars show the mean values from the CTL and FWF experiments, respectively, while hatched bars represent the difference as FWF minus CTL. Positive and negative values are enhanced import and export of freshwater across $46.5^{\circ} \mathrm{N}$, respectively. 

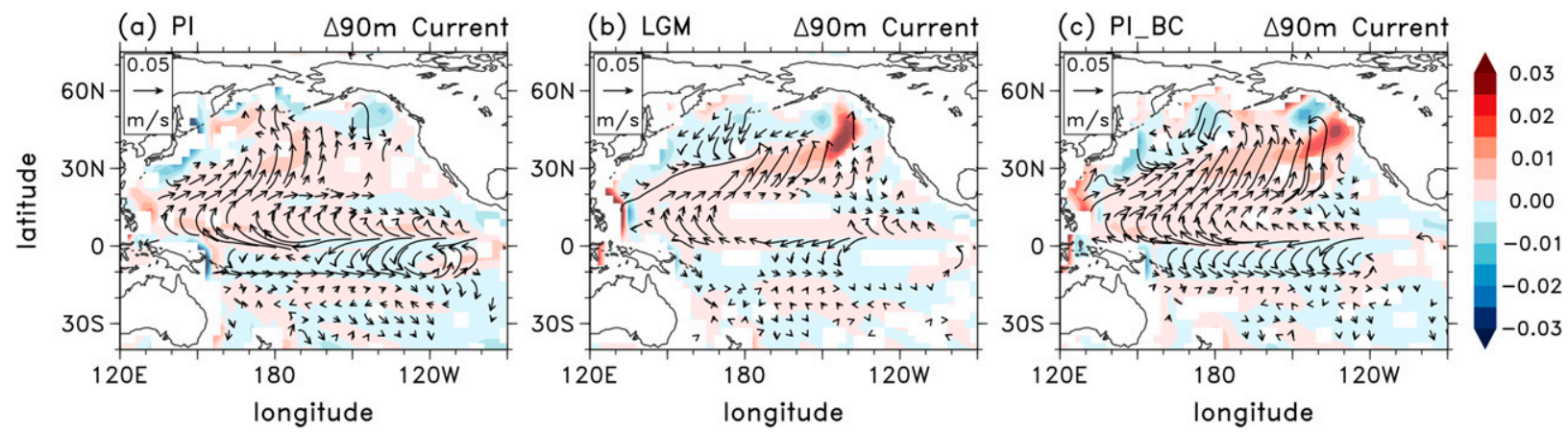

FIG. 12. Changes in mean horizontal current at 90-m depth (vectors; $\mathrm{m} \mathrm{s}^{-1}$ ) and meridional velocity at the same level (color shading; $\mathrm{m} \mathrm{s}^{-1}$ ) over the Pacific after the freshwater forcing from (a) PI, (b) LGM, and (c) PI_BC. For visual clarity, the meridional component of the vectors is shown multiplied by 10 , while the shadings show the original magnitude.

the sinking region $\left(50^{\circ}-60^{\circ} \mathrm{N}\right.$ in Figs. $\left.10 \mathrm{~b}, \mathrm{c}\right)$ and at the same time significant changes in the meridional velocities of the gyre circulation occurred in the forced simulations (Fig. 12). In all experiments, the fresher water was exported by the gyre from the North Pacific (Fig. 11). In the LGM and PI_BC experiments where PMOC developed, the import of saltier water increased as a response to the freshwater release in the NA. Although $W_{\text {gyre }}$ in the PI experiments also acted on the salinification of the North Pacific by the gyre, it was not enough to overcome the strong stratification in the sinking region (shown later).

Saenko et al. (2004) showed a significant strengthening of the northward current along the western boundary in the Pacific, especially at the latitude where the subtropical gyre was located, when the overturning circulation in the Pacific was activated. In the LOVECLIM simulations, the enhancement of the subpolar gyre was more prominent instead (Figs. 12b,c). The difference may be somehow due to the limitation of LOVECLIM in the simulation of the narrow western boundary current (WBC). The width of the WBC typically extends to only a few kilometers in the North Pacific (Ambe et al. 2004; Imawaki et al. 2013; Hu and Cui 1989), while the horizontal resolution of the ocean model is about $3^{\circ}$.

Upwelling in the Southern Ocean (SO) also contributes to the PMOC maintenance. Figure 13 shows the zonally averaged streamfunctions in the global oceans for the forced experiments. Interestingly, strong upwelling processes were found at about $60^{\circ} \mathrm{S}$ only in the cases of active PMOC (Figs. 13b,c), which implies water mass compensation between the upward and downward motions in the ocean. The sinking in the North Pacific implies mass transfer from the surface to the intermediate layer, and provided that vertical mixing in the ocean interior was not strong enough to support the upwelling branch of the circulation, as required to maintain the THC, the equilibrium state was not able to be sustained without pumping to offset it (Munk and Wunsch 1998; Wunsch 1998; Wunsch and Ferrari 2004; Marshall and Speer 2012). Alternatively, taking density conversion into account, it could be addressed as a
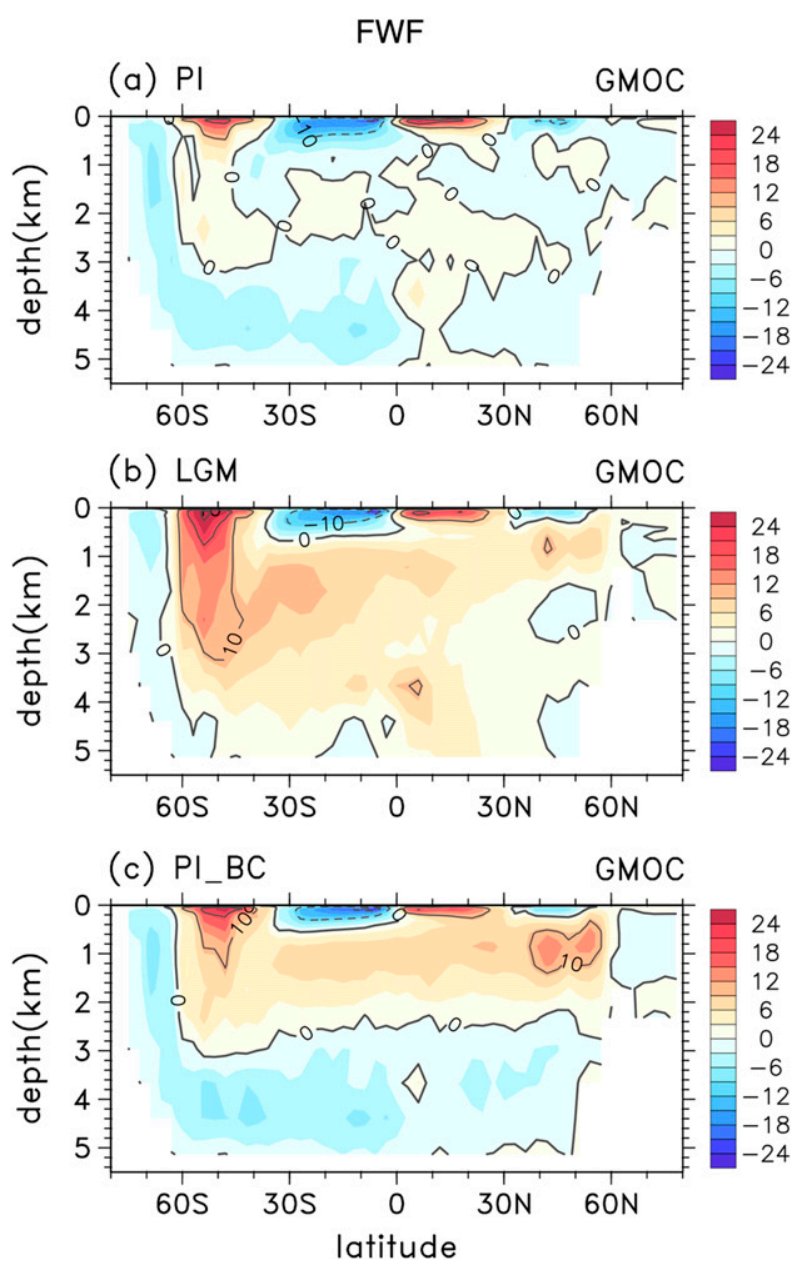

FIG. 13. Zonally integrated mean meridional streamfunction (color bar; Sv) in global oceans, obtained from the (a) PI FWF, (b) LGM FWF, and (c) PI_BC FWF experiments. 
balance between light-to-dense water conversion in the North Pacific and dense-to-light in the SO (Rintoul et al. 2001). In this light, the SO upwelling compensates for the North Pacific sinking, and hence supports the maintenance of the PMOC.

Under the current climate conditions, namely that the NA is more favorable for sinking compared to the North Pacific, it is known that the NADW formation rate is proportional to the southern upwelling intensity (Schewe and Levermann 2010; Toggweiler and Samuels 1995; Sévellec and Fedorov 2011; Toggweiler and Samuels 1993). The upwelling in the SO has been closely linked to westerly wind strength through Ekman divergence (Toggweiler and Samuels 1993, 1995; Gnanadesikan and Hallberg 2000; Rintoul et al. 2001; Sévellec and Fedorov 2011), so in this context we compared westerly wind intensities at $800 \mathrm{hPa}$.

Figure 14a represents the difference in $800-\mathrm{hPa}$ winds between LGM FWF and PI FWF, showing a stronger westerly in LGM FWF than in PI FWF around $60^{\circ} \mathrm{S}$ and $70^{\circ} \mathrm{E}-150^{\circ} \mathrm{W}$. As aforementioned, the strong westerly was dynamically linked to an upward motion in the same region (see Fig. 13). The difference in $800-\mathrm{hPa}$ winds between PI_BC FWF and PI FWF (Fig. 14b) also shows strong westerlies over the same latitudinal band as seen in Fig. 14a. However, the difference in the westerlies (Fig. 14b) seems somewhat weaker than expected from the difference in the upwelling intensity (Figs. 13a,c). Hence, it indicates that the westerlies could not solely explain the difference in the upwelling strength. Although the wind stress in PI FWF was weaker than that in PI_BC FWF, it was still strong enough to generate a shallow overturning cell at $50^{\circ} \mathrm{S}$ (Fig. 13a). However, the strength and vertical extent of this shallow overturning cell were limited, presumably due to no compensation process in other regions through subsidence, in view of mass conservation. On the other hand, in the PI_BC FWF experiment not only the substantial sinking in the North Pacific but also the stronger westerlies were present.

Here, to evaluate the effect of the westerlies, we conducted an additional PI_BC FWF experiment but the surface wind stress over the area south of $30^{\circ} \mathrm{S}$ was fixed as climatology values computed from PI FWF, in order to suppress the westerlies. In this additional experiment, both the sinking in the Pacific and the upwelling in the SO were still simulated, but their intensities were slightly reduced compared to the original PI_BC FWF (not shown here). It implied that the development of PMOC was primarily responsible for the difference in the upwelling strength between PI FWF and PI_BC FWF, while the stronger westerlies in PI_BC FWF further enhanced it. Furthermore, the

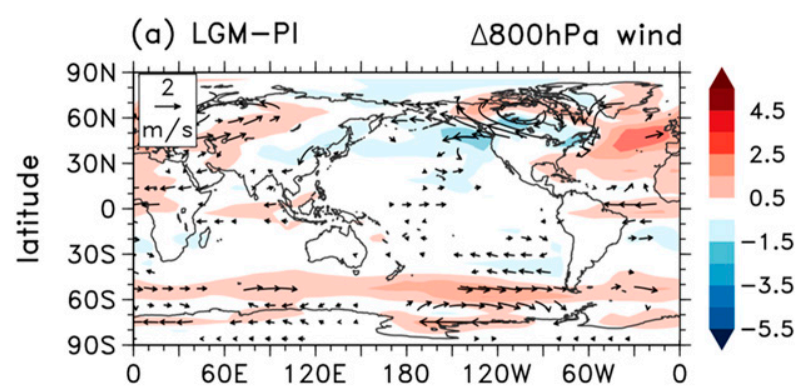

(b) PI_BC-PI $\triangle 800 \mathrm{hPa}$ wind

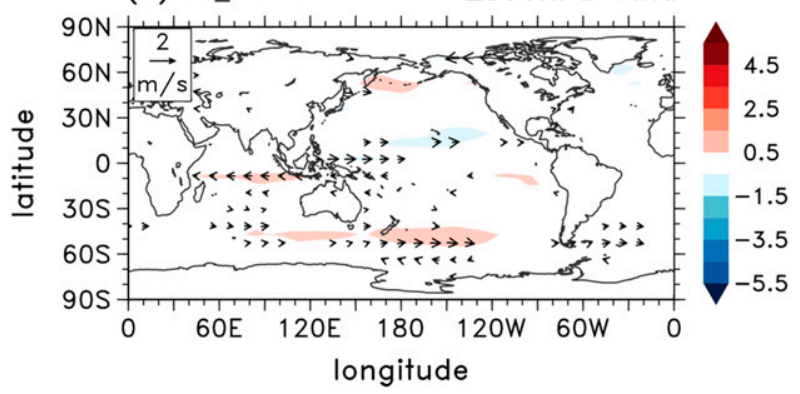

FIG. 14. (a) Arrows show differences in mean horizontal wind at $800 \mathrm{hPa}$ between LGM FWF and PI FWF. The shading indicates differences in wind speed at the same level $\left(\mathrm{m} \mathrm{s}^{-1}\right)$. (b) As in (a), but between PI_BC FWF and PI FWF.

PMOC intensity, which was defined in the Pacific north of $20^{\circ} \mathrm{N}$, was reduced by $\sim 5 \%$ compared to that from the original PI_BC FWF, supporting that the strong westerlies and resulting upwelling over the $\mathrm{SO}$ were dynamically linked to PMOC.

PI_BC FWF and LGM FWF, which are the cases with no throughflow between the Arctic and Pacific, shared a similar atmospheric feature showing anomalous westerlies, but the driving mechanism seems to be different. In the PI_BC FWF experiment, surface temperature decreased around $60^{\circ} \mathrm{S}$ after the freshwater was applied, enhancing the equator-to-pole temperature contrast (Figs. 7c and 15b), which strengthened the westerly winds around $50^{\circ} \mathrm{S}$ through the thermal wind relationship, where the gradient would have significantly increased. On the other hand, the LGM FWF produced a general warming in the SH mid-to-high latitudes (Figs. 7b and 15a), so that the strengthened westerlies could not be explained by the temperature change associated with freshwater forcing-induced impact. In fact, the SO upwelling and low-level winds in the LGM FWF were not so different from those in the LGM CTL, suggesting that the freshwater forcing is nothing to do with SO upwelling and strong westerlies. Actually, the mean meridional temperature gradient over the Southern Hemisphere in the LGM simulation was larger than that in the PI and PI_BC simulations, and thus the mean westerly is stronger. The stronger mean westerlies over 
(a) LGM

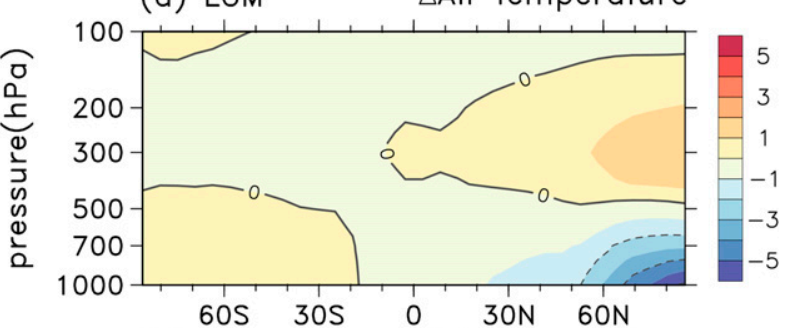

(b) PI_BC

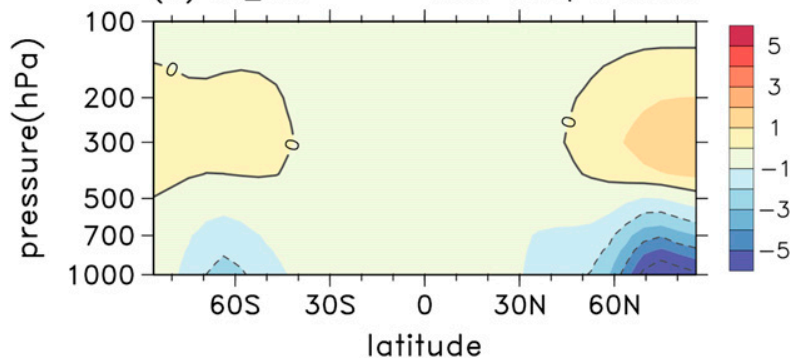

FIG. 15. Changes in zonally averaged air temperature (color bar; K) after the freshwater forcing in (a) LGM and (b) PI_BC.

the SO during the Last Glacial Maximum were also consistent with the previous study by Kim et al. (2017). Therefore, both SO upwelling and strong westerlies in the LGM simulation were driven not by freshwater forcing but by the boundary condition.

In Table 2, we have outlined the compensation relationship between basins for the global THC closure. As mentioned earlier, AMOC shut down in all three cases when freshwater was injected to the NA Ocean, a state marked (with an " $x$ ") in the ATL column of the table. In PI FWF, the buoyancy loss in the Pacific did not develop, and neither did the SO upwelling. Thus, the absence of deep/intermediate water formation was balanced with the absence of dense-to-light water transformation. In LGM FWF and PI_BC FWF, where the westerly winds further forced the Ekman current northward, they both existed, so that equilibrium was achieved by canceling each other. The offset between downward $(\downarrow)$ and upward $(\uparrow)$ arrows represents this in the table.

So far, we have introduced the factors that led to the emergence of active PMOC in the freshwater-forced
LGM and PI_BC simulations. Here, we have examined another aspect of just what hinders PMOC evolution in the forced PI simulation. An indirect component was already proposed in the previous paragraph, namely, that the water supply from the south did not work. In addition, since the BS, a gateway between the Arctic and the North Pacific, was open in PI FWF, the fresher water inflow could reach the Pacific and directly influence oceanic circulation. In Fig. 16, snapshots of the sea surface salinity (SSS) obtained from the PI FWF simulation are displayed. At year 0 (i.e., before the forcing), SSS less than 32 psu was not observed in the Pacific. However, as the freshwater was injected into the NA, relatively fresh water from the Arctic Ocean flowed into the North Pacific through the mixing and advection over the Bering Strait, and propagated farther south. Accordingly, a freshwater cap appeared at the surface of the North Pacific where the MLD would have deepened if PMOC were activated (see Fig. 10), and the stratification was largely enhanced. The relatively small buoyancy loss in the sinking region (Fig. 5a) and the salinity import through the gyre circulation (Fig. 11) were easily canceled out by the fresher water inflow through BS. In conclusion, the fail of PMOC emergence in PI FWF experiment is mainly attributed to the strengthened stratification in the North Pacific due to the fresher water infiltration.

\section{Discussion}

Our results demonstrated that the relationship between the Atlantic and Pacific circulations could not be determined by a simple frame. Previous studies suggested an antiphased relationship between AMOC and PMOC (Cessi et al. 2004; Saenko et al. 2004; Okazaki et al. 2010; Hu et al. 2012a; Sinha et al. 2012), and our work has also shown a reversal in the major sinking region between the Atlantic and Pacific, supporting the conceptual "Pacific-Atlantic seesaw" relationship, under the LGM and PI_BC conditions. Under the PI condition, however, even after AMOC collapse due to the freshwater forcing, PMOC was not activatedwhich was consistent with the study of $\mathrm{Hu}$ et al. (2012a), which proposed that BS closure was a necessary

TABLE 2. A conceptual description of vertical motions in each basin when freshwater over the NA is engaged, highlighting compensation between upwelling and downwelling. ATL = Atlantic, PCF = Pacific, SO = Southern Ocean, MOC = meridional overturning circulation; $\mathrm{x}=$ no sinking/rising branch of MOC; $\downarrow=$ sinking branch of MOC; and $\uparrow=$ rising branch of MOC.

\begin{tabular}{lcccc}
\hline \hline Boundary conditions & ATL & PCF & SO & Net \\
\hline PI & $\mathrm{x}$ & $\mathrm{x}$ & $\mathrm{x}$ & No compensation required \\
LGM & $\mathrm{x}$ & $\downarrow$ & $\uparrow$ & Compensated \\
PI_BC & $\mathrm{x}$ & $\downarrow$ & $\uparrow$ & Compensated \\
\hline
\end{tabular}



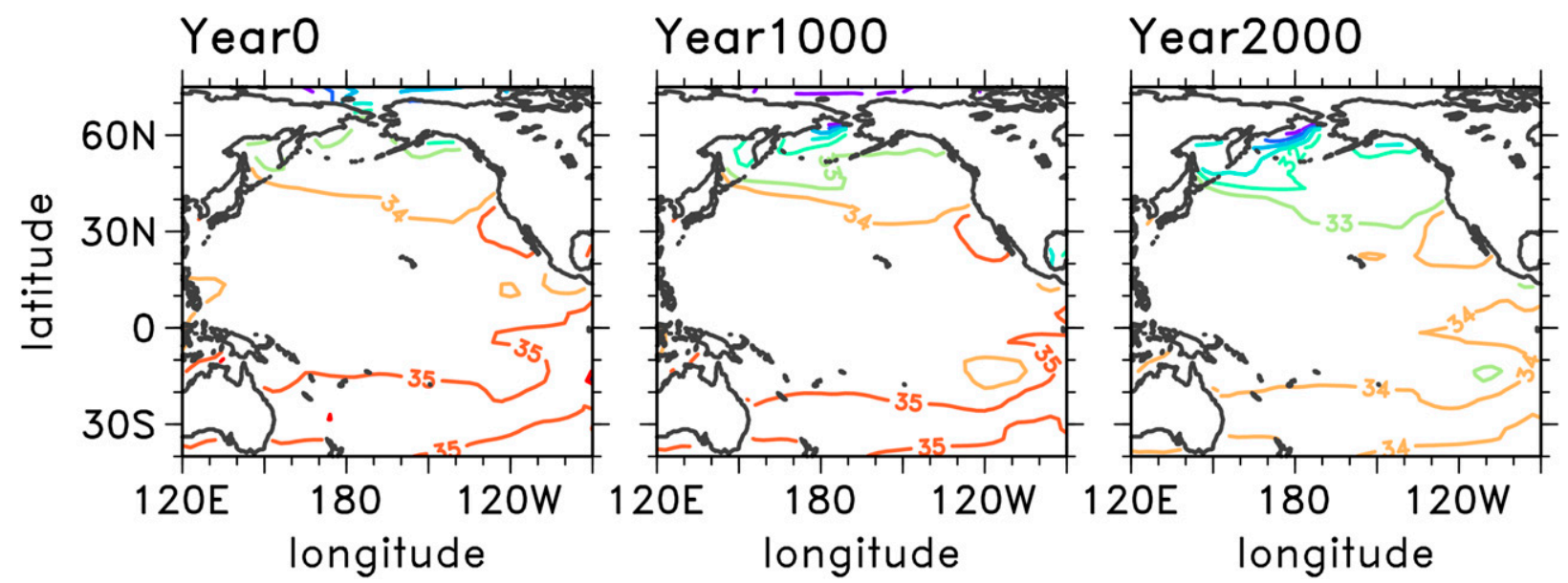

FIG. 16. Snapshots of the sea surface salinity (psu) in the North Pacific from the PI FWF simulation.

condition for the anticorrelation. Meanwhile, Huisman et al. (2009) have suggested in their idealized ocean model that four possible steady states in global THC could exist: "AMOC only," "PMOC only," "Both active," and "Both inactive/reversed." Furthermore, they also showed that the AMOC only state could be converted to the Both inactive/reversed state, but not to Both active, when freshwater forcing was applied. Similarly, the PMOC only state could be switched to the Both active state, but not to the Both inactive/reversed state.

Although the southern sinking was not striking in PI FWF (Fig. 4d), the conversion from AMOC only state to the Both inactive/reversed state in Huisman et al. (2009) could be an analog to the PI response in this study, although the other two cases remain contradictory to it. In other words, a mere seesaw relationship failed to demonstrate the PI result in this study, and the classification of AMOC only to Both inactive/reversed versus PMOC only to Both active failed to demonstrate the LGM and the PI_BC results. In this regard, it can be inferred that the possibility of PMOC and AMOC coexistence may depend on boundary conditions, model complexity, or allowance for air-sea interaction. Huisman et al. (2009) used a rectangular, ocean-only model, in which the $\mathrm{Pa}-$ cific and the Atlantic basins were connected only through their southern part (hence, with the BS closed), while the model used in our study, LOVECLIM, was a fully coupled model with more realistic geography.

In our results, the qualitative effect of the BS closure was rather linear. As seen in the PI and PI_BC responses (Figs. $4 \mathrm{~g}$ and $4 \mathrm{i}$, respectively), the changes at the ocean bottom were quite similar. The collapse of the preexisting, counterclockwise circulation was inevitable, as long as the boundary conditions (except for the BS) were those of the preindustrial period. In addition to that, it looked as if the PI_BC response had a PMOC cell superposed onto the PI response pattern. A similar clockwise cell in the upper $2 \mathrm{~km}$ found in the LGM response (Fig. 4h) supported the concept that the PI_BC pattern could be a mixture of two components of the response to the freshwater forcing: one generated by the general climatic conditions, and the other by the BS closure.

For more quantitative analysis, additional experiments could be helpful. For example, a set of experiments in which the efficiency of inflow exchange gradually changed would allow us to measure its linear effect. Although the LGM and PI_BC responses had some resemblance in terms of PMOC's spatial structure, the intensities of the circulation were different, which may have been caused by the inherent complexity of the system (e.g., interaction between intermediate and bottom cells) or by subtle discrepancies in boundary conditions. In the PI_BC simulations, the BS closure was artificially done by a flux cutoff at a certain latitude in the model, whereas in the LGM simulations it was facilitated by the lowered sea level. Therefore, there were differences in sea level, and in the latitude of the northern boundary of the Pacific. Aside from these artifacts, the unperturbed climate condition may also have had an influence. Additional analysis on the ocean stratification revealed that the Pacific Ocean was more stable in LGM CTL than in PI_BC CTL. A relatively weak stable condition in the PI_BC CTL Pacific Ocean could have been more favorable for PMOC, allowing PI_BC FWF to have stronger circulation. This is consistent with the previous findings by Schmittner et al. (2007), who compared the effect of mean stratification in the North Pacific.

So far, a fundamental process that induced the atmospheric response has been unclear so that the causes 
of the anomalous low sea level pressure (SLP) development in the northeastern Pacific (Figs. $6 \mathrm{~b}, \mathrm{c}$ ) or of the positive PDO-like SST pattern (Figs. $7 \mathrm{~b}, \mathrm{c}$ ) have not been clearly addressed. Actually, those might be the results of PMOC, rather than the causes, but it is hard to identify whether the ocean drives the atmosphere, or the other way around, as we are dealing with a quasi-steady state only. Nonetheless, they can still act as positive feedback to support PMOC by resulting in a reduction of the precipitation. Indeed, the intensity of these feedbacks was positively related to the PMOC intensity. That is to say, the surface buoyancy loss (Fig. 5c), as well as the saltier water influx by the gyre circulation (Fig. 12c), was stronger in PI_BC FWF where PMOC was more vigorous, in comparison to the LGM FWF experiment (Figs. 1 and 4). The mass compensation by the SO upwelling seems inconsistent at first glance because it was more active and deeper in LGM FWF, but the mean climate conditions should be taken in to account together. Because of the strong thermal gradient during the Last Glacial Maximum, the surface westerlies were much stronger in LGM FWF, resulting in a deeper and stronger upwelling. In addition, the weakly stratified Pacific Ocean in PI_BC FWF may promote diapycnal mixing to compensate the subsidence. Thus, the absence of the positive correlation between the upwelling and sinking intensities does not counter their dynamical relationship.

Also, the SH temperature response shown in Figs. 7c and $12 \mathrm{~b}$ was somewhat the opposite of what one would expect. When AMOC shut down and its heat transport was halted as well, $\mathrm{SH}$ temperature was expected to increase, whereas the $\mathrm{NH}$ should cool, according to the so-called hemispheric seesaw. In PI_BC FWF, although the PMOC intensity measured by the index was weaker than that of AMOC (Fig. 1c), PMOC actually transported more heat to the north relative to the AMOC of PI_BC CTL, possibly contributing to the more cooling in the Southern Hemisphere. Since our focus was mainly on how PMOC reacted and what process supported its maintenance, we did not take this analysis further, although it is certainly worthy of future investigation.

In any event, differences in the abruptness and rate of AMOC change were not considered here. Our main target of analysis was the stable state, which was specified based on the AMOC index (shaded intervals in Fig. 1); that is, the years 2000-2200 in each simulation were considered as comparable, quasi-equilibrium states. Each simulation had different AMOC footprints, however, in terms of the intensity and the rate of its reaction to the forcing. In our experimental setting, a steady freshwater flux forcing was controlled uniformly. Its Atlantic responses were not necessarily the same, and it acted as an indirect forcing to the Pacific, so the results shown above may include differences in AMOC.

The BS, in particular, has been known to play a crucial role in determining the trajectory of the AMOC transition (Hu et al. 2012a,b). Opening and closing the BS affected the transition rate from one steady state to another. If the BS was open, fresher water could flow from the Atlantic to the Pacific, and could loosen the AMOC shutdown, and similarly, when freshwater was extracted from the Atlantic Ocean under an inactive AMOC condition, AMOC recovery could occur less drastically, by exporting the anomalous saline forcing to the Pacific. In reverse, the BS closure could promote a rapid transition between AMOC on and off states, which was also apparent from our experiments (Fig. 1). We believe that such differences in detail would not alter the qualitative results on PMOC's response. Nonetheless, consideration of such an effect may help to understand abrupt climate changes and their successive influences.

Finally, Knudson and Ravelo (2015) have reported paleoclimatic evidence that showed a major contribution from brine rejection in North Pacific Intermediate Water formation. In our experiments, neither of the two cases with PMOC showed sea ice formation in the North Pacific that could provide enough salinity to the surface water. As discussed by them, such a discrepancy might have been produced by the model's low resolution, and its lack of ability to simulate sea ice formation appropriately.

\section{Summary}

In this study, we strategically compared PMOC's response to freshwater release in the North Atlantic Ocean under different boundary conditions, using a fully coupled model of intermediate complexity. PI and PI_BC shared general climatic features, such as the distribution of average surface temperature and the spatial pattern of AMOC. By comparing these two, we could distinguish effects induced solely by the BS. The LGM and PI_BC boundary conditions did not allow water exchange via the BS; thus, by comparing these two, we could see if the BS effect was robust under different climate states. Taking the CTL simulations of each boundary condition as the starting point, a linearly increasing and decreasing freshwater flux was uniformly distributed to the NA region, with the result that AMOC collapsed in all three experiments, while its counterpart, PMOC, developed only in two experiments: LGM FWF and PI_BC FWF. Although the importance of the BS on oceanic circulations has been pointed out by previous 


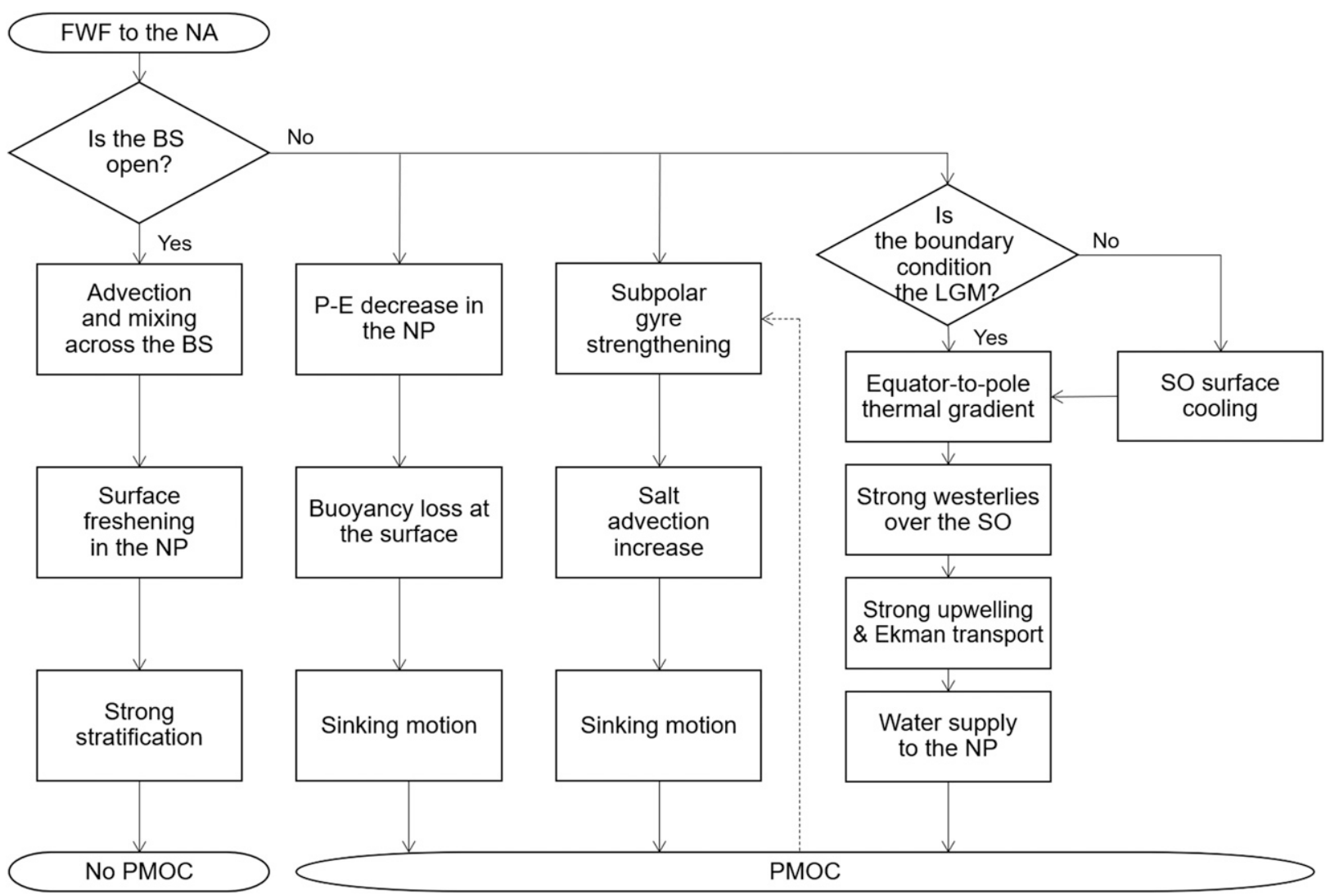

FIG. 17. A flowchart on processes for the PMOC development and breakdown cases. A feedback process is denoted by a dotted line. NP represents the North Pacific and LGM represents the Last Glacial Maximum (other abbreviations are as in the text).

studies, our results were quite remarkable because the only factor that the LGM and PI_BC experiments shared in their boundary conditions was closure of the BS. Even though PI_BC had much more in common with PI in terms of climate, their responses to the forcing were noticeably different. Nonetheless, careful interpretation is needed here, since the influence of the BS may depend on the location of freshwater release.

To understand the causes of the different responses, we categorized our questions into two parts: 1) How is the active PMOC maintained in the LGM and in PI_BC simulations? 2) What prevented it in PI?

Our answers have been summarized in Fig. 17. The key processes necessary to sustain the sinking in the North Pacific were atmospheric forcing and the oceanic gyre circulation to increase seawater density, and constant SO upwelling. The surface buoyancy loss by the atmosphere was induced by the redistribution of the pressure system as well as by reduced baroclinic instability. With development of PMOC, the enhanced subpolar North Pacific gyre supplied more salinity in the sinking region, acting as positive feedback. The SO upwelling enabled active PMOC at equilibrium by compensating the subsiding water mass. It was also associated with wind enhancement, either by predefined boundary conditions (LGM) or by low-level cooling in the SH (PI_BC). Together, they produced a condition conducive to PMOC existence. On the other hand, if the BS was open, the freshwater flowed toward the convection site in the Pacific, thereby providing an environment that was unfavorable condition for PMOC development.

Our results have implied certain aspects of the interbasin relationships of the oceans, and have shown that simplified, conceptual categorizations were not successful in explaining every case simulated by a coupled model - which, in turn, may imply that there is no such standardized pattern in the oceanic teleconnection. Finally, as the PMOC response in PI_BC showed a mixture of that which resulted in LGM and PI, our results have suggested linearity in the BS effect on Pacific oceanic circulation.

Acknowledgments. This research was supported by the Basic Science Research Program through the National Research Foundation of Korea (NRF-2017R1A2A2A05069383, 
NRF-2018R1A5A1024958). H.-J. Kim was supported by the Hyundai Motor Chung Mong-Koo Foundation. The authors also appreciate S.-Y. Jun, D. M. Roche, and A. Timmermann for help with the model setup.

\section{REFERENCES}

Aharon, P., 2003: Meltwater flooding events in the Gulf of Mexico revisited: Implications for rapid climate changes during the last deglaciation. Paleoceanography, 18, 1079, https://doi.org/ 10.1029/2002PA000840.

Ambe, D., S. Imawaki, H. Uchida, and K. Ichikawa, 2004: Estimating the Kuroshio axis south of Japan using combination of satellite altimetry and drifting buoys. J. Oceanogr., 60, 375382, https://doi.org/10.1023/B:JOCE.0000038343.31468.fe.

Bakker, P., and Coauthors, 2016: Fate of the Atlantic meridional overturning circulation: Strong decline under continued warming and Greenland melting. Geophys. Res. Lett., 43, 12 252-12 260, https://doi.org/10.1002/2016GL070457.

Bitz, C. M., J. C. H. Chiang, W. Cheng, and J. J. Barsugli, 2007: Rates of thermohaline recovery from freshwater pulses in modern, Last Glacial Maximum, and greenhouse warming climates. Geophys. Res. Lett., 34, L07708, https://doi.org/ 10.1029/2006GL029237.

Böhm, E., and Coauthors, 2015: Strong and deep Atlantic meridional overturning circulation during the last glacial cycle. Nature, 517, 73-76, https://doi.org/10.1038/nature14059.

Böning, C. W., E. Behrens, A. Biastoch, K. Getzlaff, and J. L. Bamber, 2016: Emerging impact of Greenland meltwater on deepwater formation in the North Atlantic Ocean. Nat. Geosci., 9, 523-527, https://doi.org/10.1038/ngeo2740.

Boyer, T., S. Levitus, J. Antonov, R. Locarnini, A. Mishonov, H. Garcia, and S. A. Josey, 2007: Changes in freshwater content in the North Atlantic Ocean 1955-2006. Geophys. Res. Lett., 34, L16603, https://doi.org/10.1029/2007GL030126.

Braconnot, P., and Coauthors, 2007: Results of PMIP2 coupled simulations of the mid-Holocene and Last Glacial MaximumPart 1: Experiments and large-scale features. Climate Past, 3, 261-277, https://doi.org/10.5194/cp-3-261-2007.

_ S. P. Harrison, M. Kageyama, P. J. Bartlein, V. MassonDelmotte, A. Abe-Ouchi, B. Otto-Bliesner, and Y. Zhao, 2012: Evaluation of climate models using palaeoclimatic data. Nat. Climate Change, 2, 417-424, https://doi.org/10.1038/ nclimate1456.

Broecker, W. S., 1997: Thermohaline circulation, the Achilles heel of our climate system: Will man-made $\mathrm{CO}_{2}$ upset the current balance? Science, 278, 1582-1588, https://doi.org/10.1126/ science.278.5343.1582.

Brovkin, V., A. Ganapolski, and Y. Svirezhev, 1997: A continuous climate-vegetation classification for use in climate-biosphere studies. Ecol. Modell., 101, 251-261, https://doi.org/10.1016/ S0304-3800(97)00049-5.

Burls, N. J., A. V. Fedorov, D. M. Sigman, S. L. Jaccard, R. Tiedemann, and G. H. Haug, 2017: Active Pacific meridional overturning circulation (PMOC) during the warm Pliocene. Sci. $A d v ., 3$, e1700156, https://doi.org/10.1126/sciadv.1700156.

Caesar, L., S. Rahmstorf, A. Robinson, G. Feulner, and V. Saba, 2018: Observed fingerprint of a weakening Atlantic Ocean overturning circulation. Nature, 556, 191-196, https://doi.org/ 10.1038/s41586-018-0006-5.

Cessi, P., K. Bryan, and R. Zhang, 2004: Global seiching of thermocline waters between the Atlantic and the Indian-Pacific
Ocean Basins. Geophys. Res. Lett., 31, L04302, https://doi.org/ 10.1029/2003GL019091.

Chikamoto, M. O., and Coauthors, 2012: Variability in North Pacific intermediate and deep water ventilation during Heinrich events in two coupled climate models. Deep. Sea Res. II, 6164, 114-126, https://doi.org/10.1016/j.dsr2.2011.12.002.

Deschamps, P., and Coauthors, 2012: Ice-sheet collapse and sealevel rise at the Bølling warming 14,600 years ago. Nature, $\mathbf{4 8 3}$, 559-564, https://doi.org/10.1038/nature10902.

Deser, C., M. A. Alexander, S.-P. Xie, and A. S. Phillips, 2010: Sea surface temperature variability: Patterns and mechanisms. Annu. Rev. Mar. Sci., 2, 115-143, https://doi.org/10.1146/ annurev-marine-120408-151453.

de Vries, P., and S. L. Weber, 2005: The Atlantic freshwater budget as a diagnostic for the existence of a stable shut down of the meridional overturning circulation. Geophys. Res. Lett., 32, L09606, https://doi.org/10.1029/2004GL021450.

Donohoe, A., J. Marshall, D. Ferreira, and D. Mcgee, 2013: The relationship between ITCZ location and cross-equatorial atmospheric heat transport: From the seasonal cycle to the last glacial maximum. J. Climate, 26, 3597-3618, https://doi.org/ 10.1175/JCLI-D-12-00467.1.

Eady, E. T., 1949: Long waves and cyclone waves. Tellus, 1, 33-52, https://doi.org/10.3402/tellusa.v1i3.8507.

Emile-Geay, J., and Coauthors, 2016: Links between tropical Pacific seasonal, interannual and orbital variability during the Holocene. Nat. Geosci., 9, 168-173, https://doi.org/10.1038/ ngeo2608.

Fairbanks, G. R., 1989: A 17,000-year glacio-eustatic sea level record; influence of glacial melting rates on the Younger Dryas event and deep-ocean circulation. Nature, 342, 637-642, https://doi.org/10.1038/342637a0.

Flower, B. P., C. Williams, H. W. Hill, and D. W. Hastings, 2013: Laurentide Ice Sheet meltwater and the Atlantic meridional overturning circulation during the last glacial cycle: A view from the Gulf of Mexico. Abrupt Climate Change: Mechanisms, Patterns, and Impacts, Meteor. Monogr., Vol. 193, Amer, Geophys. Union, 39-56, https://doi.org/10.1029/ 2010GM001016.

Freeman, E., L. C. Skinner, A. Tisserand, T. Dokken, A. Timmermann, L. Menviel, and T. Friedrich, 2015: An Atlantic-Pacific ventilation seesaw across the last deglaciation. Earth Planet. Sci. Lett., 424, 237-244, https://doi.org/ 10.1016/j.epsl.2015.05.032.

Frierson, D. M. W., and Coauthors, 2013: Contribution of ocean overturning circulation to tropical rainfall peak in the Northern Hemisphere. Nat. Geosci., 6, 940-944, https://doi.org/ 10.1038/ngeo1987.

Gnanadesikan, A., and R. W. Hallberg, 2000: On the relationship of the Circumpolar Current to Southern Hemisphere winds in coarse-resolution ocean models. J. Phys. Oceanogr., 30, 2013-2034, https://doi.org/10.1175/1520-0485(2000)030<2013: OTROTC $>2.0 . \mathrm{CO} ; 2$.

Goosse, H., and T. Fichefet, 1999: Importance of ice-ocean interactions for the global ocean circulation: A model study. J. Geophys. Res., 104, 23 337-23355, https://doi.org/10.1029/ 1999JC900215.

—_ and Coauthors, 2010: Description of the Earth system model of intermediate complexity LOVECLIM version 1.2. Geosci. Model Dev., 3, 603-633, https://doi.org/10.5194/gmd-3-6032010.

Gregory, J. M., and Coauthors, 2005: A model intercomparison of changes in the Atlantic thermohaline circulation in response 
to increasing atmospheric $\mathrm{CO}_{2}$ concentration. Geophys. Res. Lett., 32, L12703, https://doi.org/10.1029/2005GL023209.

Hawkins, E., R. S. Smith, L. C. Allison, J. M. Gregory, T. J. Woollings, H. Pohlmann, and B. de Cuevas, 2011: Bistability of the Atlantic overturning circulation in a global climate model and links to ocean freshwater transport. Geophys. Res. Lett., 38, L10605, https://doi.org/10.1029/2011GL047208.

Held, I. M., 2001: The partitioning of the poleward energy transport between the tropical ocean and atmosphere. J. Atmos. Sci., 58, 943-948, https://doi.org/10.1175/1520-0469(2001) 058<0943:TPOTPE $>2.0$. CO;2.

Hoegh-Guldberg, O., and Coauthors, 2019: Impacts of $1.5^{\circ} \mathrm{C}$ global warming on natural and human systems. Global warming of $1.5^{\circ} \mathrm{C}$. An IPCC Special Report on the impacts of global warming of $1.5^{\circ} \mathrm{C}$ above pre-industrial levels and related global greenhouse gas emission pathways, in the context of strengthening the global response to the threat of climate change, sustainable development, and efforts to eradicate poverty. V. Masson-Delmotte et al., Eds., WMO, in press, https://www.ipcc.ch/sr15/chapter/chapter-3/.

$\mathrm{Hu}$, A., and Coauthors, 2012a: Role of the Bering Strait on the hysteresis of the ocean conveyor belt circulation and glacial climate stability. Proc. Natl. Acad. Sci. USA, 109, 6417-6422, https://doi.org/10.1073/pnas.1116014109.

_, G. A. Meehl, W. Han, A. Abe-Ouchi, C. Morrill, Y. Okazaki, and M. O. Chikamoto, 2012b: The Pacific-Atlantic seesaw and the Bering Strait. Geophys. Res. Lett., 39, L03702, https:// doi.org/10.1029/2011GL050567.

Hu, D., and M. Cui, 1989: The Western Boundary Current in the far western Pacific Ocean. Proc. Western Int. Meeting and Workshop on TOGA COARE. J. Picaut, R. Lukas, and T. Delcroix, Eds., Noumea, New Caledonia, Institut Francais de Recheriche Scientifique pour le Developpement en Cooperation, 123-134.

Huisman, S. E., H. A. Dijkstra, A. von der Heydt, and W. P. M. de Ruijter, 2009: Robustness of multiple equilibria in the global ocean circulation. Geophys. Res. Lett., 36, L01610, https:// doi.org/10.1029/2008GL036322.

Imawaki, S., A. S. Bower, L. Beal, and B. Qiu, 2013: Western boundary currents. Ocean Circulation and Climate: $A$ 21st century perspective, 2nd ed., G. Siedler et al., Eds., Academic Press, 305-338.

Jackson, L. C., R. S. Smith, and R. A. Wood, 2017: Ocean and atmosphere feedbacks affecting AMOC hysteresis in a GCM. Climate Dyn., 49, 173-191, https://doi.org/10.1007/s00382-0163336-8.

Johannessen, O. M., and Coauthors, 2004: Arctic climate change: Observed and modelled temperature and sea-ice variability. Tellus, 56A, 328-341, https://doi.org/10.1111/j.1600-0870.2004.00060.x.

Josey, S. A., J. J.-M. Hirschi, B. Sinha, A. Duchez, J. P. Grist, and R. Marsh, 2018: The recent Atlantic cold anomaly: Causes, consequences, and related phenomena. Annu. Rev. Mar. Sci., 10, 475-501, https://doi.org/10.1146/annurev-marine-121916063102 .

Kageyama, M., and Coauthors, 2013: Climatic impacts of fresh water hosing under Last Glacial Maximum conditions: A multi-model study. Climate Past, 9, 935-953, https://doi.org/ 10.5194/cp-9-935-2013.

Kawabe, M., and S. Fujio, 2010: Pacific Ocean circulation based on observation. J. Oceanogr., 66, 389-403, https://doi.org/10.1007/ s10872-010-0034-8.

Kienast, S. S., T. Friedrich, N. Dubois, P. S. Hill, A. Timmermann, A. C. Mix, and M. Kienast, 2013: Near collapse of the meridional
SST gradient in the eastern equatorial Pacific during Heinrich Stadial 1. Paleoceanography, 28, 663-674, https://doi.org/10.1002/ 2013PA002499.

Kim, H., and S.-I. An, 2013: On the subarctic North Atlantic cooling due to global warming. Theor. Appl. Climatol., 114, 919, https://doi.org/10.1007/s00704-012-0805-9.

Kim, S.-J., S.-Y. Jun, and B.-M. Kim, 2017: Sensitivity of Southern Hemisphere westerly wind to boundary conditions for the last glacial maximum. Quat. Int., 459, 165-174, https://doi.org/ 10.1016/j.quaint.2017.04.001.

Knudson, K. P., and A. C. Ravelo, 2015: North Pacific Intermediate Water circulation enhanced by the closure of the Bering Strait. Palaeoceanography, 30, 1287-1304, https://doi.org/10.1002/ 2015PA002840.

Lindzen, R. S., and B. Farrell, 1980: A simple approximate result for the maximum growth rate of baroclinic instabilities. J. Atmos. Sci., 37, 1648-1654, https://doi.org/10.1175/15200469(1980)037<1648:ASARFT>2.0.CO;2.

Liu, W., and Z. Liu, 2013: A diagnostic indicator of the stability of the Atlantic meridional overturning circulation in CCSM3. J. Climate, 26, 1926-1938, https://doi.org/10.1175/JCLI-D-1100681.1.

- and $\mathrm{A} . \mathrm{Hu}, 2015$ : The role of the PMOC in modulating the deglacial shift of the ITCZ. Climate Dyn., 45, 3019-3034, https://doi.org/10.1007/s00382-015-2520-6.

— , and A. V. Fedorov, 2019: Global impacts of Arctic sea ice loss mediated by the Atlantic meridional overturning circulation. Geophys. Res. Lett., 46, 944-952, https://doi.org/10.1029/ 2018GL080602.

, S.-P. Xie, Z. Liu, and J. Zhu, 2017: Overlooked possibility of a collapsed Atlantic meridional overturning circulation in warming climate. Sci. Adv., 3, e1601666, https://doi.org/ 10.1126/sciadv.1601666.

— A. Fedorov, and F. Sévellec, 2019: The mechanisms of the Atlantic meridional overturning circulation slowdown induced by Arctic sea ice decline. J. Climate, 32, 977-996, https:// doi.org/10.1175/JCLI-D-18-0231.1.

Mantua, N. J., S. R. Hare, Y. Zhang, J. M. Wallace, and R. C. Francis, 1997: Pacific interdecadal climate oscillation with impacts on salmon production. Amer. Meteor. Soc, 78, 1069-1079, https://doi.org/10.1175/1520-0477(1997)078<1069: APICOW $>2.0 . \mathrm{CO} ; 2$

Marshall, J., and K. Speer, 2012: Closure of the meridional overturning circulation through Southern Ocean upwelling. Nat. Geosci., 5, 171-180, https://doi.org/10.1038/ngeo1391.

— A. Donohoe, D. Ferreira, and D. McGee, 2014: The ocean's role in setting the mean position of the Inter-Tropical Convergence Zone. Climate Dyn., 42, 1967-1979, https://doi.org/ 10.1007/s00382-013-1767-z.

Marson, J. M., I. Wainer, M. M. Mata, and Z. Liu, 2014: The impacts of deglacial meltwater forcing on the South Atlantic Ocean deep circulation since the Last Glacial Maximum. Climate Past, 10, 1723-1734, https://doi.org/10.5194/cp-10-1723-2014.

Marzocchi, A., and M. Jansen, 2017: Connecting Antarctic sea ice to deep ocean circulation in modern and glacial climate simulations. Geophys. Res. Lett., 44, 6286-6295, https://doi.org/ 10.1002/2017GL073936.

Max, L., and Coauthors, 2012: Sea surface temperature variability and sea-ice extent in the subarctic northwest Pacific during the past 15,000 years. Paleoceanography, 27, PA3213, https:// doi.org/10.1029/2012PA002292.

L. Lembke-Jene, J. R. Riethdorf, R. Tiedemann, D. Nürnberg, H. Kühn, and A. Mackensen, 2014: Pulses of 
enhanced North Pacific Intermediate Water ventilation from the Okhotsk Sea and Bering Sea during the last deglaciation. Climate Past, 10, 591-605, https://doi.org/10.5194/cp-10-591-2014.

McGee, D., A. Donohoe, J. Marshall, and D. Ferreira, 2014: Changes in ITCZ location and cross-equatorial heat transport at the Last Glacial Maximum, Heinrich Stadial 1, and the midHolocene. Earth Planet. Sci. Lett., 390, 69-79, https://doi.org/ 10.1016/j.epsl.2013.12.043.

Meehl, G. A., and Coauthors, 2007: Global climate projections. Climate Change 2007: The Physical Science Basis. S. Solomon et al., Eds., Cambridge University Press, 747-845.

Menviel, L., M. H. England, K. J. Meissner, A. Mouchet, and J. Yu, 2014: Atlantic-Pacific seesaw and its role in outgassing $\mathrm{CO}_{2}$ during Heinrich events. Paleoceanography, 29, 58-70, https:// doi.org/10.1002/2013PA002542.

Mikolajewicz, U., T. J. Crowley, A. Schiller, and R. Voss, 1997: Modelling teleconnections between the North Atlantic and North Pacific during the Younger Dryas. Nature, 387, 384-387, https://doi.org/10.1038/387384a0.

, M. Gröger, E. Maier-Reimer, G. Schurgers, M. Vizcaíno, and A. Winguth, 2006: Long-term effects of anthropogenic $\mathrm{CO}_{2}$ emissions simulated with a complex Earth system model. Climate Dyn., 25, 599-633, https://doi.org/10.1007/s00382-0060204-y.

Muglia, J., and A. Schmittner, 2015: Glacial Atlantic overturning increased by wind stress in climate models. Geophys. Res. Lett., 42, 9862-9869, https://doi.org/10.1002/2015GL064583.

Munk, W., and C. Wunsch, 1998: Abyssal recipes II: Energetics of tidal and wind mixing. Deep. Sea Res. I, 45, 1977-2010, https:// doi.org/10.1016/S0967-0637(98)00070-3.

Newman, M., and Coauthors, 2016: The Pacific decadal oscillation, revisited. J. Climate, 29, 4399-4427, https://doi.org/10.1175/ JCLI-D-15-0508.1.

Okazaki, Y., A. Timmermann, L. Menviel, N. Harada, A. AbeOuchi, M. O. Chikamoto, A. Mouchet, and H. Asahi, 2010: Deepwater formation in the North Pacific during the last glacial termination. Science, 329, 200-204, https://doi.org/ 10.1126/science. 1190612

Opsteegh, J. D., R. J. Haarsma, F. M. Selten, and A. Kattenberg, 1998: ECBILT: A dynamic alternative to mixed boundary conditions in ocean models. Tellus, 50A, 348-367, https:// doi.org/10.3402/tellusa.v50i3.14524.

Park, D.-S. R., S. Lee, and S. B. Feldstein, 2015: Attribution of the recent winter sea ice decline over the Atlantic sector of the Arctic Ocean. J. Climate, 28, 4027-4033, https://doi.org/ 10.1175/JCLI-D-15-0042.1.

Peltier, W. R., 2004: Global glacial isostasy and the surface of the ice-age Earth: The ICE-5G (VM2) Model and GRACE. Annu. Rev. Earth Planet. Sci., 32, 111-149, https://doi.org/ 10.1146/annurev.earth.32.082503.144359.

Praetorius, S. K., and A. C. Mix, 2014: Synchronization of North Pacific and Greenland climates preceded abrupt deglacial warming. Science, 345, 444-448, https://doi.org/10.1126/ science. 1252000 .

Rahmstorf, S., 1996: On the freshwater forcing and transport of the Atlantic thermohaline circulation. Climate Dyn., 12, 799-811, https://doi.org/10.1007/s003820050144.

Rintoul, S., C. Hughes, and D. Olbers, 2001: The Antarctic Circumpolar Current. Ocean Circulation and Climate. G. Siedler, J. A. Church, and J. Gould, Eds., Academic Press, 271-301.

Saenko, O. A., A. Schmittner, and A. J. Weaver, 2004: The Atlantic-Pacific seesaw. J. Climate, 17, 2033-2038, https:// doi.org/10.1175/1520-0442(2004)017<2033:TAS>2.0.CO;2.
Sampe, T., H. Nakamura, A. Goto, and W. Ohfuchi, 2010: Significance of a midlatitude SST frontal zone in the formation of a storm track and an eddy-driven westerly jet. J. Climate, $\mathbf{2 3 ,}$ 1793-1814, https://doi.org/10.1175/2009JCLI3163.1.

Sarnthein, M., B. Schneider, and P. M. Grootes, 2013: Peak glacial $14 \mathrm{C}$ ventilation ages suggest major draw-down of carbon into the abyssal ocean. Climate Past, 9, 2595-2614, https://doi.org/ 10.5194/cp-9-2595-2013.

Schewe, J., and A. Levermann, 2010: The role of meridional density differences for a wind-driven overturning circulation. Climate Dyn., 34, 547-556, https://doi.org/10.1007/s00382-0090572-1.

Schmittner, A., E. D. Galbraith, S. W. Hostetler, T. F. Pedersen, and R. Zhang, 2007: Large fluctuations of dissolved oxygen in the Indian and Pacific Oceans during Dansgaard-Oeschger oscillations caused by variations of North Atlantic Deep Water subduction. Paleoceanography, 22, https://doi.org/ 10.1029/2006PA001384

_ , T. A. M. Silva, K. Fraedrich, E. Kirk, and F. Lunkeit, 2011: Effects of mountains and ice sheets on global ocean circulation. J. Climate, 24, 2814-2829, https://doi.org/10.1175/ 2010JCLI3982.1.

Schneider, T., T. Bischoff, and G. H. Haug, 2014: Migrations and dynamics of the intertropical convergence zone. Nature, $\mathbf{5 1 3}$, 45-53, https://doi.org/10.1038/nature13636.

Sévellec, F., and A. V. Fedorov, 2011: Stability of the Atlantic meridional overturning circulation and stratification in a zonally averaged ocean model: Effects of freshwater flux, Southern Ocean winds, and diapycnal diffusion. Deep. Sea Res. II, 58, 1927-1943, https://doi.org/10.1016/j.dsr2. 2010.10.070.

- — - and W. Liu, 2017: Arctic sea-ice decline weakens the Atlantic Meridional Overturning Circulation. Nat. Climate Change, 7, 604-610, https://doi.org/10.1038/nclimate3353.

Simmonds, I., and E. P. Lim, 2009: Biases in the calculation of Southern Hemisphere mean baroclinic eddy growth rate. Geophys. Res. Lett., 36, L01707, https://doi.org/10.1029/ 2008 GL036320.

Sinha, B., A. T. Blaker, J. J. M. Hirschi, S. Bonham, M. Brand, S. Josey, R. S. Smith, and J. Marotzke, 2012: Mountain ranges favour vigorous Atlantic meridional overturning. Geophys. Res. Lett., 39, L02705, https://doi.org/10.1029/2011GL050485.

Stommel, H., 1961: Thermohaline convection with two stable regimes of flow. Tellus, 13, 224-230, https://doi.org/10.3402/ tellusa.v13i2.9491.

Stroeve, J. C., M. C. Serreze, M. M. Holland, J. E. Kay, J. Malanik, and A. P. Barrett, 2012: The Arctic's rapidly shrinking sea ice cover: A research synthesis. Climatic Change, 110, 1005-1027, https://doi.org/10.1007/s10584-011-0101-1.

Sung, M.-K., S.-I. An, B.-M. Kim, and S.-H. Woo, 2014: A physical mechanism of the precipitation dipole in the western United States based on PDO-storm track relationship. Geophys. Res. Lett., 41, 4719-4726, https://doi.org/10.1002/2014GL060711.

Talley, L. D., 2013: Closure of the global overturning circulation through the Indian, Pacific, and Southern Ocean. Oceanography, 26, 80-97, https://doi.org/10.5670/oceanog.2013.07.

Thornalley, D. J. R., and Coauthors, 2018: Anomalously weak Labrador Sea convection and Atlantic overturning during the past 150 years. Nature, 556, 227-230, https://doi.org/10.1038/ s41586-018-0007-4.

Timmermann, A., and H. Goosse, 2004: Is the wind stress forcing essential for the meridional overturning circulation? Geophys. Res. Lett., 31, L04303, https://doi.org/10.1029/2003GL018777. 
U. Krebs, F. Justino, H. Goosse, and T. Ivanochko, 2005: Mechanisms for millennial-scale global synchronization during the last glacial period. Paleoceanography, 20, PA4008, https://doi.org/10.1029/2004PA001090.

—, T. Friedrich, O. E. Timm, M. O. Chikamoto, A. Abe-Ouchi, and A. Ganopolski, 2014: Modeling obliquity and $\mathrm{CO}_{2}$ effects on Southern Hemisphere climate during the past $408 \mathrm{ka}$. J. Climate, 27, 1863-1875, https://doi.org/10.1175/JCLI-D-1300311.1.

Toggweiler, J. R., and B. Samuels, 1993: Is the magnitude of the deep outflow from the Atlantic Ocean actually governed by Southern Hemisphere winds? The Global Carbon Cycle, M. Heimann, Ed., Springer-Verlag, 303-332.

- and - 1995: Effect of Drake Passage on the global thermohaline circulation. Deep. Sea Res. I, 42, 477-500, https:// doi.org/10.1016/0967-0637(95)00012-U.

Van As, D., and Coauthors, 2014: Increasing meltwater discharge from the Nuuk region of the Greenland ice sheet and implications for mass balance (1960-2012). J. Glaciol., 60, 314-322, https://doi.org/10.3189/2014JoG13J065.

von der Heydt, A., and H. A. Dijkstra, 2006: Effect of ocean gateways on the global ocean circulation in the late Oligocene and early Miocene. Paleoceanography, 21, PA1011, https:// doi.org/10.1029/2005PA001149.

- and - 2008: The effect of gateways on ocean circulation patterns in the Cenozoic. Global Planet. Change, 62, 132-146, https://doi.org/10.1016/j.gloplacha.2007.11.006.

Warren, B. A., 1983: Why is no deep water formed in the North Pacific? J. Mar. Res., 41, 327-347, https://doi.org/10.1357/ 002224083788520207

Wunsch, C., 1998: The work done by the wind on the oceanic general circulation. J. Phys. Oceanogr., 28, 2332-2340, https://doi.org/ 10.1175/1520-0485(1998)028<2332:TWDBTW >2.0.CO;2.

— , and R. Ferrari, 2004: Vertical mixing, energy, and the general circulation of the oceans. Annu. Rev. Fluid Mech., 36, 281-314, https://doi.org/10.1146/annurev.fluid.36.050802.122121.

Yang, H., K. Wang, H. Dai, Y. Wang, and Q. Li, 2016: Wind effect on the Atlantic meridional overturning circulation via sea ice and vertical diffusion. Climate Dyn., 46, 3387-3403, https:// doi.org/10.1007/s00382-015-2774-z.

Zhang, R., and T. Delworth, 2005: Simulated tropical response to a substantial weakening of the Atlantic thermohaline circulation. J. Climate, 18, 1853-1860, https://doi.org/10.1175/ JCLI3460.1. 